\title{
Influence of Processing Parameters on Laser Direct Joining of CFRTP and Stainless Steel
}

\author{
Liyuan Sheng $\mathbb{D},{ }^{1}$ Junke Jiao $\mathbb{D}^{2},{ }^{2}$ Beining Du $\mathbb{D},{ }^{1}$ Feiya Wang $\mathbb{D},{ }^{2}$ and Qiang Wang ${ }^{2}$ \\ ${ }^{1}$ Shenzhen Institute, Peking University, Shenzhen 518057, China \\ ${ }^{2}$ Ningbo Institute of Materials Technology and Engineering, Chinese Academy of Sciences, Ningbo 315201, China
}

Correspondence should be addressed to Liyuan Sheng; lysheng@hotmail.com

Received 7 February 2018; Revised 4 April 2018; Accepted 5 April 2018; Published 16 May 2018

Academic Editor: Akihiko Kimura

Copyright ( 2018 Liyuan Sheng et al. This is an open access article distributed under the Creative Commons Attribution License, which permits unrestricted use, distribution, and reproduction in any medium, provided the original work is properly cited.

The CFRTP and the stainless steel were joined by the fiber laser, and the effect of processing parameters on the joint quality was investigated in detail. The heat-affected zone on the stainless steel and the microstructure of the joint interface were examined and analyzed. The results showed that the laser joining process refines the microstructure of the fusion and heat-affected zones in the stainless steel. And the tensile strength of the joint was affected greatly by the laser power and scanning speed but slightly by the clamping pressure. With the PPS additive, the joint shear strength could be improved, and the optimal PPS additive thickness is $300 \mu \mathrm{m}$. With the best parameters, joint with a shear strength of 15-17 MPa could be obtained as the laser power is 320-350 W, the scanning speed is $4-5 \mathrm{~mm} / \mathrm{s}$, the clamping pressure is about $0.5 \mathrm{Mpa}$, and the additive PPS thickness is about $300 \mu \mathrm{m}$.

\section{Introduction}

Recently, the carbon fiber reinforced polymer (CFRP) has attracted lots of attentions because of its advantages, such as low density, high strength-to-weight ratios, excellent corrosion resistance, high specific stiffness, good environmental degradation, and fatigue resistance $[1,2]$. It has been applied as the structural material in many fields, such as automotive, aerospace, airplane, and concrete structure [3-5]. However, the wide application of the CFRP inevitably encounters the problem of how to join the CFRP with the metal-based components.

The most common joining methods between the CFRP and metals include the mechanical joining, adhesive bonding, and thermal joining. The mechanical joining technology has advantages of high joint strength and long working time, but it has some drawbacks such as stress concentration and fiber damage [6-8]. The research of Marannano [9] investigated the double-lap joints of aluminum and CFRP laminate by rivets arrays and exhibited that the initial delamination near the CFRP hole edge could influence the strength of the joint because the crack or delamination could grow rapidly along the initial damage region. Kweon et al. [10] studied the adhesively bonded $\mathrm{Al} / \mathrm{CFRP}$ double-lap joint assisted with bolt insertion and revealed that the strength of hybrid joints could be improved when the mechanical joint was stronger than that of the simple adhesively bonded joint. However, the joint of CFRP and metal by predrilling and mechanical fastening would destroy the microstructure of CFRP and influence its strength and fatigue properties [11]. And the mechanical joining processes involve manual steps such as predrilling and subsequent insertion of extra joining elements and require additional materials (rivets, bolts, etc.) that increase the production time, costs, and structure weight. Recently, the fast mechanical joining process such as self-pierce riveting and clinching was proposed to overcome this problem [12-14]. Compared with the mechanical joining method, the adhesive bonding technology has a better stress distribution, good fatigue life, corrosion resistance, and high strength-toweight ratio; however, it has some drawbacks such as long curing time and high environmental impact $[15,16]$.

The polyphenylene sulfite- (PPS-) based carbon fiber reinforced thermoplastic (CFRTP) is a kind of carbon fiber reinforced polymer with good thermoprocess feature and main advantages of CFRP, so it can be joined with metals by 
thermal processing. The thermal joining methods such as friction-assisted joining and laser-assisted joining have been applied in joining CFRTP and metals. In the friction-assisted joining process, heat is produced by means of a rotating tool that slightly plunges a metal sheet, which heats up by friction. Lots of works have been done to increase the joint strength and reduce the joining defects [17-19]. However, friction-assisted joining is a contact process, which will cause some destruction to metals. In the laser-assisted joining process, a laser source is used to irradiate the metal part, and an external clamping force is applied to enhance the joining strength. The laser heating maybe also destroys the microstructure of the metals without proper joining parameters. To improve the joining quality and avoid the thermal defects, lots of researches have been performed in laserassisted joining of CFRTP and metals.

Lambiase et al. [20, 21] applied the laser-assisted direct joining method in joining the 304 stainless steel/polycarbonate and CFRTP/polycarbonate, and the main process conditions (laser power and scanning speed) influencing the direct-bonding quality, dimensions, and presence of defect were investigated. Katayama and Kawahito [22] exhibited that the laser irradiated on stainless steel could generate $\mathrm{Cr}_{2} \mathrm{O}_{3}$ transition layer on the interface of plastic/stainless steel. Moreover, the research of Tan et al. [23] revealed that the existence of the Cr layer on the steel surface enhanced the shear strength of the CFRP/steel joint by the Cr-O-PA6T bonding along the joint interface. The Roesner et al. [24] demonstrated that the machined microgrooves on the metal surface increased the strength of the laser joined plastic/aluminum joint to $24 \mathrm{MPa}$. Whatever the change in the processing parameter, surface morphology, and surface modification, the air bubble is inevitably generated in the CFRTP. The study of Tan et al. [25] revealed that the heat from the laser would result in rapid temperature increase, which could generate $\mathrm{CO}_{2}, \mathrm{NH}_{3}$, and $\mathrm{H}_{2} \mathrm{O}$ in the CFRP and promote the air bubbles and porosity. The recent research [26] also exhibited that the processing parameter could exert obvious effect on the size and amount of the porosity. Based on the former researches [27-31], the formation of defects along the joining interface influenced the mechanical properties obviously. Then, it became important to decrease the formation of porosity during the laser joining CFRTP and metals.

As mentioned above, the previous investigations mainly focused on the interface and the bonding mechanism of the CFRTP. However, till now, few works have been carried out to study the effect of laser joining processing parameters. Therefore, in the present paper, the fiber laser was employed to fabricate the joint of the CFRTP and stainless steel. The influence of laser power, laser scanning speed, clamping pressure, and PPS additive on joint interface and mechanical properties were analyzed to explore the optimization processing parameters.

\section{Materials and Methods}

2.1. Materials. In this study, the CFRTP panels with the PPS matrix reinforced by T700 carbon fibers were cut in a size of
TABLE 1: The chemical composition of the 304 stainless steel (wt.\%).

\begin{tabular}{lccccccc}
\hline $\mathrm{C}$ & $\mathrm{Si}$ & $\mathrm{Mn}$ & $\mathrm{Cr}$ & $\mathrm{Ni}$ & $\mathrm{S}$ & $\mathrm{P}$ & $\mathrm{Fe}$ \\
\hline 0.07 & 0.56 & 0.78 & 18.33 & 8.10 & 0.006 & 0.032 & Balanced \\
\hline
\end{tabular}

$50 \mathrm{~mm} \times 30 \mathrm{~mm} \times 3 \mathrm{~mm}$, and the 304 stainless steel plate with a size of $50 \mathrm{~mm} \times 30 \mathrm{~mm} \times 2 \mathrm{~mm}$ was prepared. The stainless steel surface for bonding was scratch brushed by the \#120 abrasive paper to increase the roughness. The chemical composition of the 304 stainless steel is shown in Table 1. Both the stainless steel and the CFRTP samples were cleaned by the absolute ethyl alcohol before joining to remove the greasy dirt. The CFRTP is composed of the PPS matrix and 15 layers T700 carbon fibers, which is weaved with the intersected structure. The carbon fiber is wrapped by the PPS, and the average thickness of single layer is $0.2 \mathrm{~mm}$. The interlayer PPS is added between the CFRTP and the stainless steel to increase the melting PPS amount and enhance the joining strength. The thickness of the PPS changes from 0 to $450 \mu \mathrm{m}$.

2.2. Experimental Procedures. The laser joining of stainless steel and CFRTP was carried out on a fiber laser welding system. This system comprises a 1410RABB robot, $500 \mathrm{~W}$ fiber laser (continuous wave laser machine and the wavelength is $1080 \mathrm{~nm}$ ), a laser processing head (The focal length is $120 \mathrm{~mm}$ ), an air-actuated clamp, and a cooling system. The schematic diagram of the joining of stainless steel and CFRP by laser is shown in Figure 1. Firstly, the CFRTP overlaid with PPS additive on surface was placed on the laser welding system, and the stainless steel plate was placed above the PPS additive. After that, the stainless steel, PPS additive, and CFRTP were clamped by the air-actuated clamp which has a groove with a size of $60 \mathrm{~mm} \times 10 \mathrm{~mm} \times 5 \mathrm{~mm}$ in the upper one. The clamping pressure could be adjusted by controlling the air-actuator. During the laser joining, the laser beam would scan on the surface of stainless steel in the groove with the argon gas flow velocity of $30 \mathrm{~L} / \mathrm{min}$. The laser power (LP), laser scanning speed (LSS), clamping pressure (CP), and thickness of PPS additive were changed to investigate the effect of these processing parameters on the joining quality. The detailed experimental parameters and the thickness of PPS additive are listed in Table 2. To identify the effect of different welding parameters on the joining quality, the single factor variable method was used in the present research. In all laser joining specimens, the defocusing amount is $-20 \mathrm{~mm}$ (the laser beam diameter is $500 \mu \mathrm{m}$ ).

The microstructure and morphology of PPS additive, CFRTP and stainless steel, and CFRTP joint were characterized by the optical microscopy (OM), scanning electron microscopy (SEM), and tensile test. The specimen for crosssectional observation was cut from the stainless steel and CFRTP joint and polished by the conventional metallographic method. The Phenom Pro SEM was employed to observe the PPS additive, CFRTP, microstructure of laser-scanned stainless steel, and the morphology of joint interface. The tensile test was performed on the CMT5105 electronic universal testing machine to obtain the shear strength. The shear 


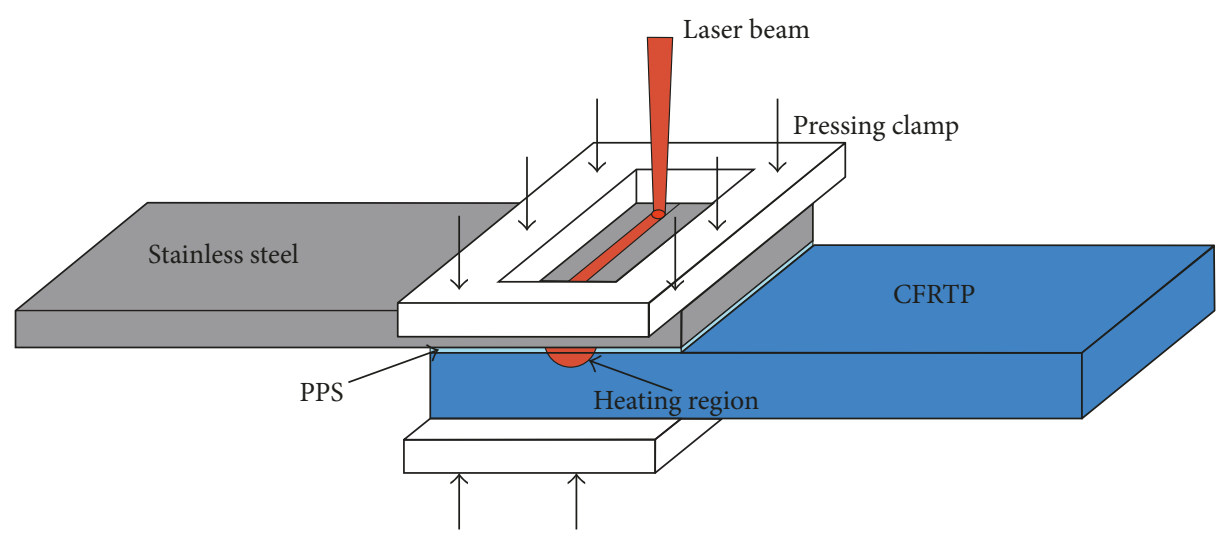

FIgURE 1: The schematic diagram of stainless steel and CFRTP laser joining.

TABLE 2: The detailed processing parameters of laser joining stainless steel and CFRTP.

\begin{tabular}{lcccc}
\hline Sample & $\begin{array}{c}\text { Laser } \\
\text { power }(\mathrm{W})\end{array}$ & $\begin{array}{c}\text { Laser } \\
\text { scanning } \\
\text { speed }(\mathrm{mm} / \mathrm{s})\end{array}$ & $\begin{array}{c}\text { Clamping } \\
\text { pressure } \\
(\mathrm{MPa})\end{array}$ & $\begin{array}{c}\text { Thickness } \\
\text { of PPS }(\mu \mathrm{m})\end{array}$ \\
\hline A1 & 290 & 5 & 0.5 & 300 \\
$\mathrm{~A} 2$ & 320 & 5 & 0.5 & 300 \\
$\mathrm{~A} 3$ & 350 & 5 & 0.5 & 300 \\
A4 & 380 & 5 & 0.5 & 300 \\
A5 & 410 & 5 & 0.5 & 300 \\
B1 & 320 & 3 & 0.5 & 300 \\
B2 & 320 & 4 & 0.5 & 300 \\
B3 & 320 & 5 & 0.5 & 300 \\
B4 & 320 & 6 & 0.5 & 300 \\
B5 & 320 & 7 & 0.5 & 300 \\
C1 & 320 & 5 & 0.5 & 300 \\
C2 & 320 & 5 & 0.6 & 300 \\
C3 & 320 & 5 & 0.7 & 300 \\
C4 & 320 & 5 & 0.8 & 300 \\
C5 & 320 & 5 & 0.9 & 300 \\
D1 & 320 & 5 & 0.5 & 0 \\
D2 & 320 & 5 & 0.5 & 150 \\
D3 & 320 & 5 & 0.5 & 300 \\
D4 & 320 & 5 & 0.5 & 450 \\
\hline
\end{tabular}

strength test was referred to the GB/T7124-86 and ASTM F2255-2005 (2010) standards. The tensile test was carried out in air with the initial strain rate of $2 \times 10^{-3} / \mathrm{s}$ at room temperature. Three specimens of same condition were tested to obtain the shear strength data. The Stemi 2000 OM was applied to observe the debonding surface of the tensile specimen.

2.3. Numerical Simulation. Though the temperature of stainless steel surface could be detected during the laser joining, the temperature distribution in the stainless steel, PPS additive, and CFRTP could not be tested effectively. In order to explain the influence of the laser joining process, the numerical simulation was carried out to analyze the temperature distribution in the laser joining region. The mathematical model, the boundary conditions, and the parameters in the simulation have been detailed in the previous study [27]. The main parameters in the simulation were defined as bellow: the initial temperature is $20^{\circ} \mathrm{C}$, the reflective coefficient of the stainless steel laser is $10 \%$, the convection coefficient is $10 \mathrm{~W} /\left(\mathrm{m}^{2} * \mathrm{~K}\right)$, and the thermal radiation coefficient is 0.9 . The temperature distribution was calculated by using the software ANSYS. A three-dimensional element SOLID70 was used in this work. In the laser travelling path, the size of element was optimized to balance the simulating precision and the computational efficiency. The thermophysical parameters of the PPS and T700 are shown in Table 3.

\section{Results and Discussion}

3.1. Analysis of the Laser Joined Stainless Steel and CFRTP Sample. The typical microstructures of PPS-based CFRTP and PPS additive are shown in Figure 2. Clearly, the PPSbased CFRTP is mainly composed of black-grey carbon fiber and white-grey PPS matrix, as shown in Figure 2(a). From the SEM image, it can be found that the carbon fibers are overlapped layer by layer, and most carbon fibers are packed and bonded together by the PPS. Based on the macroscopic observation, the layer of carbon fiber is weaved as decussate structure. The layer of carbon fiber is about $200 \mu \mathrm{m}$ in thickness. The observation of the layer of carbon fiber exhibits that they have the average size of $6 \mu \mathrm{m}$ in diameter, as shown in Figure 2(b). Moreover, the distribution of PPS in the CFRTP is not uniform and the interface of the carbon fiber layer prefers to be the vacancy of PPS. The observation of the torn PPS-based CFRTP exhibits that the carbon fiber has good integrity with regular arrangement, as shown in Figure 2(c). The SEM observation of the PPS additive reveals that the wires of PPS are overlapped randomly and there is relative high porosity as shown in Figure $2(\mathrm{~d})$. Based on the SEM image, the PPS wire has the size of $20-30 \mu \mathrm{m}$ in diameter.

The macrograph of the laser joined stainless steel and CFRTP is shown in Figure 3. It can be clearly seen that the laser scanning results in the ignited feature in the stainless steel which has obvious oxidation on the track of laser scanning as shown in Figure 3(a). Observation of the side of CFRTP and PPS exhibits that the PPS has no any changes, but the PPS additive between the stainless steel and CFRTP has been melted, as shown in Figure 3(b). The temperature in 
TABLe 3: Thermophysical parameters of the PPS and T700.

\begin{tabular}{lcccccc}
\hline Material & $\begin{array}{c}\text { Specific heat } \\
\left(\mathrm{J} \cdot \mathrm{kg}^{-1} \cdot \mathrm{C}^{-1}\right)\end{array}$ & $\begin{array}{c}\text { Thermal conductivity } \\
\left(\mathrm{W} \cdot \mathrm{m}^{-1} \cdot{ }^{\circ} \mathrm{C}^{-1}\right)\end{array}$ & $\begin{array}{c}\text { Density } \\
\left(\mathrm{kg} \cdot \mathrm{m}^{-3}\right)\end{array}$ & Melting point $\left({ }^{\circ} \mathrm{C}\right)$ & $\begin{array}{c}\text { Glass transition } \\
\text { temperature }\left({ }^{\circ} \mathrm{C}\right)\end{array}$ & $\begin{array}{c}\text { Decomposition } \\
\text { temperature }\left({ }^{\circ} \mathrm{C}\right)\end{array}$ \\
\hline PPS & 1544 & 0.278 & 1350 & 280 & 170 & 400 \\
T700 & 712 & 6.5 & 1760 & 3000 & - & - \\
\hline
\end{tabular}

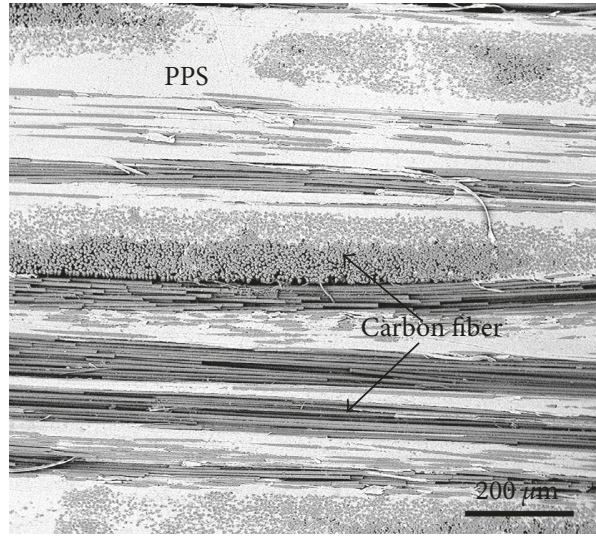

(a)

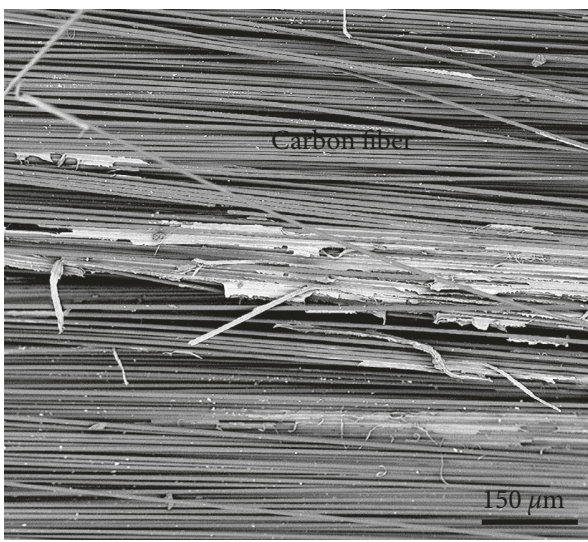

(c)

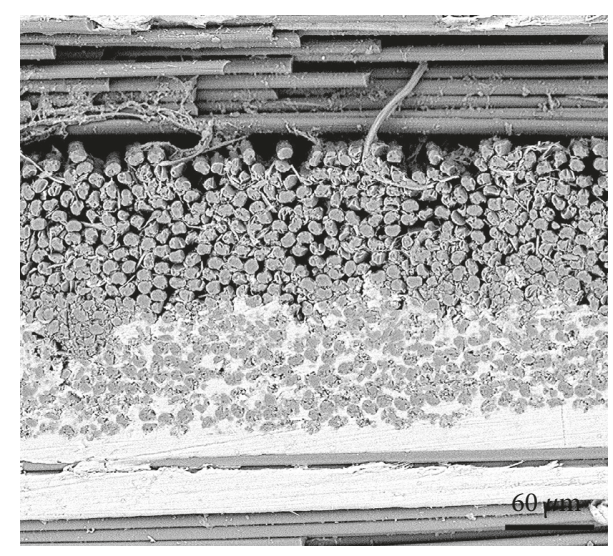

(b)

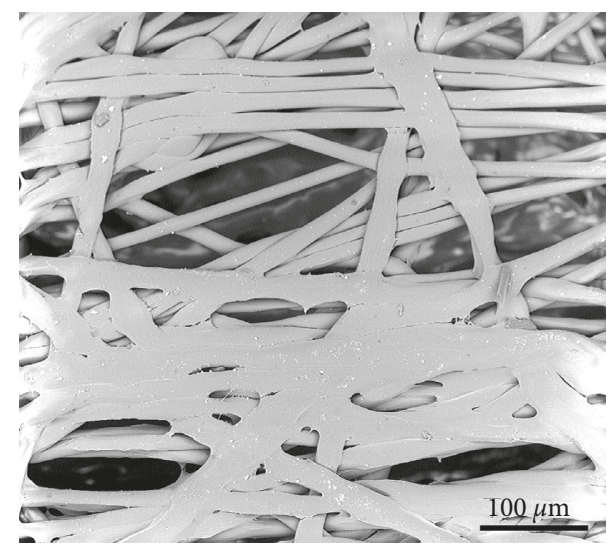

(d)

FIgURE 2: Morphology of the PPS-based CFRTP and PPS additive: (a) CFRTP with the overlapping of carbon fibers, (b) carbon fiber array, (c) carbon fibers packed by the PPS, and (d) PPS additive.

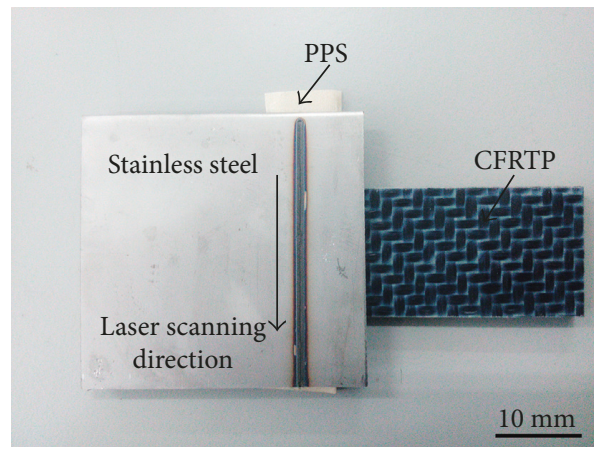

(a)

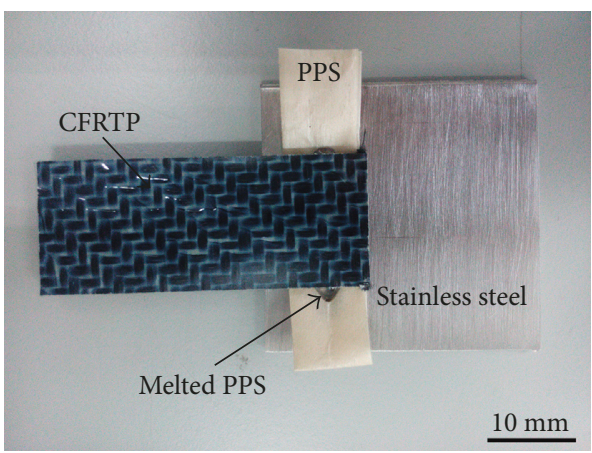

(b)

FIGURE 3: Morphology of the laser joined CFRP and stainless steel with PPS additive: (a) laser-scanned steel and (b) PPS additive with the melting feature. 


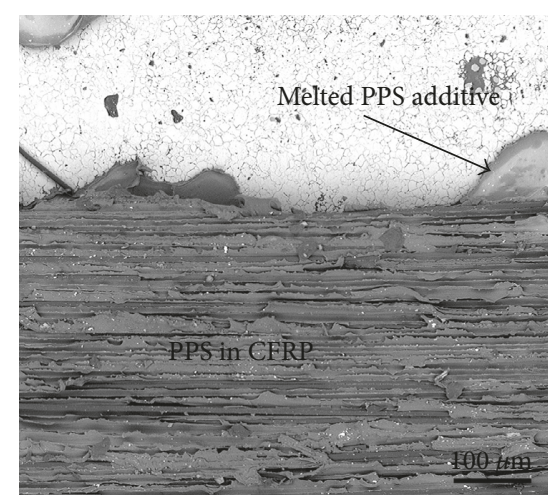

(a)

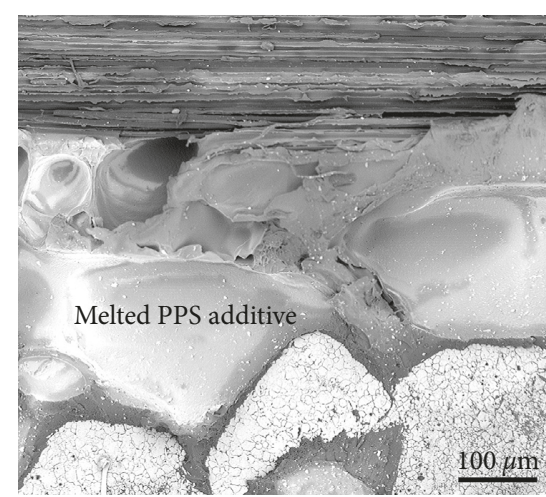

(b)

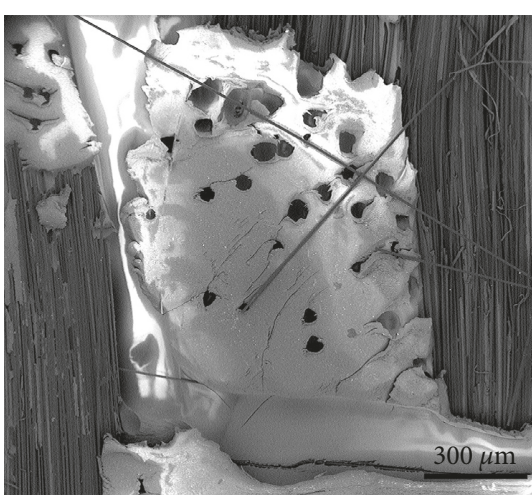

(c)

FIGURE 4: Morphology of the interface of the laser joined CFRP and stainless steel. Morphology of the CFRP on the stainless steel (a) without PPS additive and (b) with PPS additive. (c) Morphology of the PPS on the carbon fibers of the CFRP.

the center of the melting pool on the stainless steel is about $1800^{\circ} \mathrm{C}$, and the temperature decreases sharply with increasing of the depth and reaches about $400^{\circ} \mathrm{C}$ in the interface of CFRTP and the stainless steel [27]. It indicates that the heat from the laser scanning would be exceeded for the melting of the PPS additive. Then, it can ensure the PPS additive, and the surface of the CFRTP would be merged with each other and then bonded with the stainless steel. Therefore, the roughness of the stainless steel surface is helpful, which would increase the bonding surface and bonding strength.

The observation of the interface of the laser joined CFRTP and stainless steel reveals that the CFRTP still can be bonded on the stainless steel even without the PPS additive as shown in Figure 4(a). Such a joined state should be attributed to the existence of PPS in the CFRTP. During the laser joining, the laser scanning on the stainless steel would increase the temperature to about $400^{\circ} \mathrm{C}$ in the interface of the CFRTP and stainless steel, which could melt the PPS to liquid and spread on the gap of stainless steel and CFRTP [27]. Due to the limited amount of PPS in the CFRTP, the melted PPS could not spread on the gap uniformly. The addition of PPS additive would deal with the problem as shown in Figure 4(b). It can been seen that the molten PPS has filled the gap of steel and CFRTP, and moreover, some molten PPS additive has flowed out of the gap and spread on the adjacent stainless steel, but the distribution is not even. Further observation of the CFRTP interface exhibits that the molten PPS additive also fills in the vacancy of the CFRTP, as shown in Figure 4(c). Based on the observation above, there are vacancies in the CFRTP without PPS, which may influence the bonding force between the carbon fibers. Therefore, the filling of molten PPS additive in the vacancy between the carbon fibers would improve its mechanical properties.

The observation of the laser scanned stainless steel reveals that the laser scanning influences the microstructure greatly, as shown in Figure 5. It can be seen that there are fusion zone and heat-affect zone in the steel, which exhibits hemi-ellipsoidal shape, as shown in Figure 5(a). The fusion zone is marked by the blue dash line and has the width of about $450 \mu \mathrm{m}$ and the depth of about $670 \mu \mathrm{m}$. The heat-affected zone embraces the fusion zone and has the width of $100-250 \mu \mathrm{m}$, which is marked between the red dash line and blue dash line. The center of the fusion zone is about $430 \mu \mathrm{m}$ from the surface, and the core of the fusion zone exhibits nearly circle shape, which is bigger than the fusion width on the surface. Moreover, the heat-affected zone has wider size near the surface. Such morphology of fusion and heat-affected zone should be attributed to the focus position of laser. Based on the microstructure analysis, it can be found that the stainless steel exhibits homogeneous grain structure with the average size of $25 \mu \mathrm{m}$, but the laser scanning changes the microstructure, as shown in Figures 5(b) and 5(c). In the heat-affected zone, lathy ferrite mainly precipitates along the original grain boundary or twin boundary, which separates the original grain and refines the structure. Moreover, a distinct boundary formed between the heat-affected zone and matrix. With the observation proceeding to the fusion zone, ferrite becomes coarse and increases, which forms the skeletal structure. There is no distinct boundary between the heat-affected zone and fusion zone. The fusion zone is mainly distinguished by the morphology and amount of the ferrite [32]. In the fusion zone, the skeletal ferrite and cellular austenite is the main characteristic. Based on the researches [32,33], the microstructure of the fusion zone and heat-affected zone is influenced by the $\mathrm{Cr}_{\mathrm{eq}} / \mathrm{Ni}_{\mathrm{eq}}$ ratio and cooling rate. The higher $\mathrm{Cr}_{\mathrm{eq}} / \mathrm{Ni}_{\mathrm{eq}}$ ratio the stainless steel has, the more ferrite the microstructure contains. And the higher cooling rate promotes the formation of cellular structure. In the present research, the relative high $\mathrm{Cr}$ content and rapid laser scanning speed would promote the formation of ferrite with intercellular or interdendritic structure. Therefore, one can see that the skeletal ferrite separates the austenite into small cells. Such a refined structure could contribute to the improvement of the strength [34].

\subsection{Effect of Laser Power and Scanning Speed on the Laser} Joining Stainless Steel and CFRTP. In order to investigate the effect of processing parameters on the bonding force of laser joining stainless steel and CFRTP, the laser power and scanning speed were changed gradually and the shear strength of the laser joining specimens were tested to 


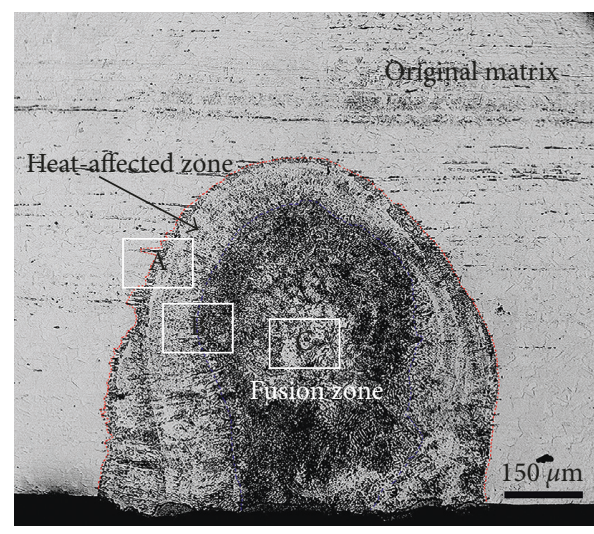

(a)

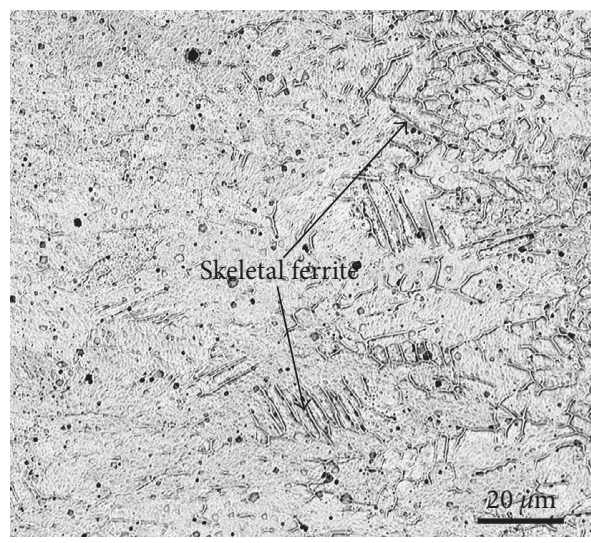

(c)

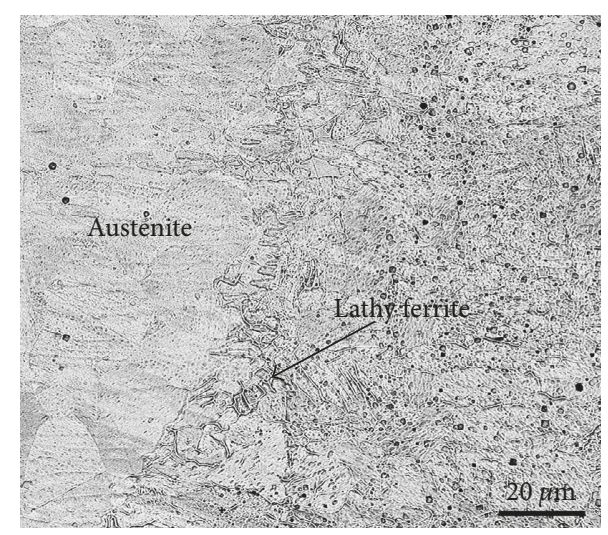

(b)

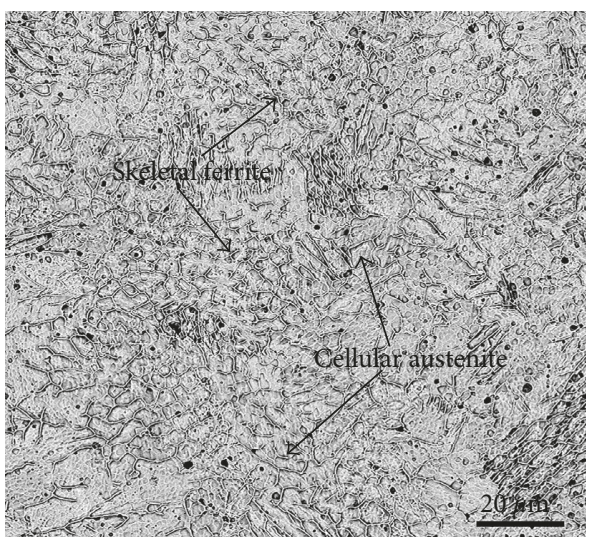

(d)

FiguRE 5: Microstructure characteristics of the laser-scanned stainless steel: (a) morphology of the heat-affected zone and fusion zone in the stainless steel; (b) microstructure of the stainless steel along the interface of the matrix and heat-affected zone (A region); (c) microstructure of the stainless steel adjacent to the fusion zone (B region); (d) microstructure of the stainless steel in the fusion zone (C region).

evaluate the bonding force. During the investigation of the effect of laser power, the laser scanning speed, clamping pressure, and thickness of PPS were set as $5 \mathrm{~mm} / \mathrm{s}, 0.5 \mathrm{MPa}$, and $300 \mu \mathrm{m}$, respectively. The shear strength of the stainless steel/CFRTP joints with different laser power is shown in Figure 6. Clearly, the variation of shear strength with power exhibits parabolic tendency. The shear strength of the stainless steel/CFRTP joint increases firstly and obtains the maximum value of $15.8 \mathrm{MPa}$ at $320 \mathrm{~W}$. When the laser power increases to $350 \mathrm{~W}$, the shear strength of the stainless steel/CFRTP joint just decreases little. After that, the shear strength decreases sharply with laser power increasing further. Based on the SEM observation above, the high laser power is beneficial to the melting of PPS additive and PPS in CFRTP, which could promote the merging of PPS additive and CFRP and then improve the bonding force between the CFRTP and the stainless steel. However, if the laser power is much higher, the improved fluidity of molted PPS and clamping pressure would result in its overflowing out of the gap between stainless steel and CFRTP, which is detrimental to the bonding.

The observations on the debonding surfaces of the stainless steel/CFRTP joints with different power show that they almost exhibit the similar feature with the debonding

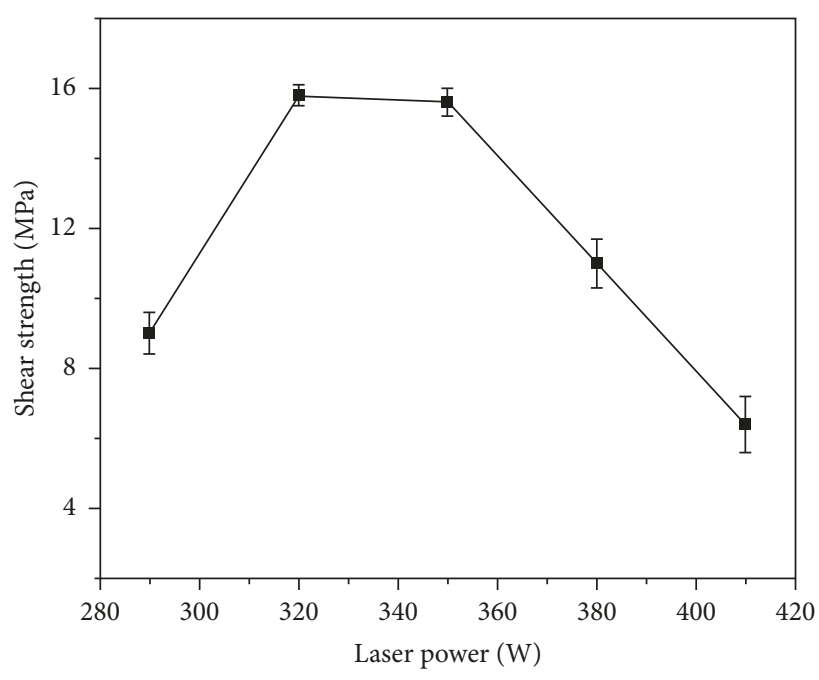

FIGURE 6: The shear strength of the stainless steel/CFRTP joints with different laser power.

along the interface of PPS, as shown in Figure 7. The difference is the fraction of PPS additive remained on the CFRTP. It can be clearly seen that the stainless steel/CFRTP 


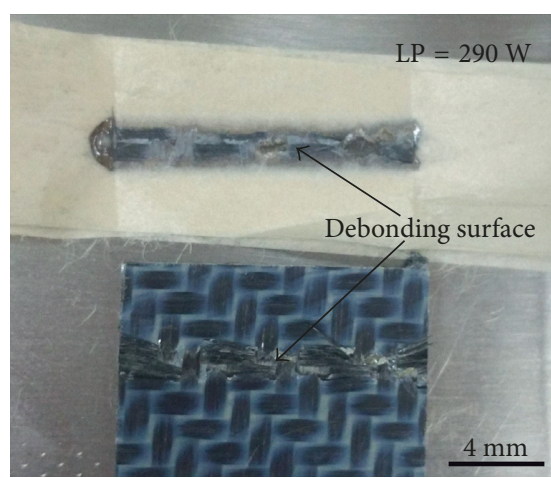

(a)

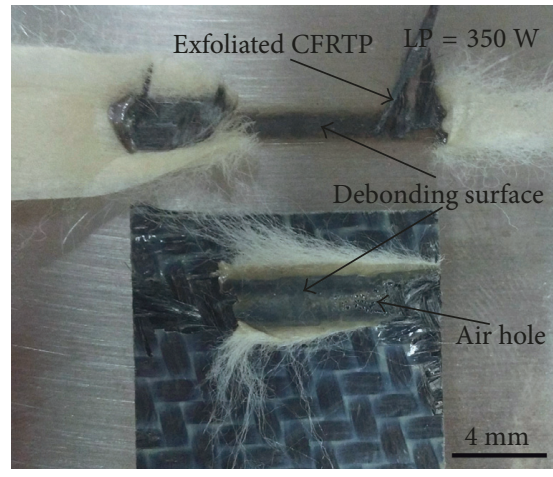

(c)

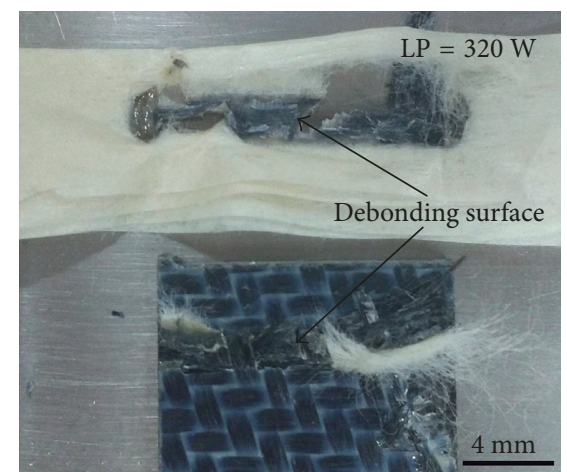

(b)

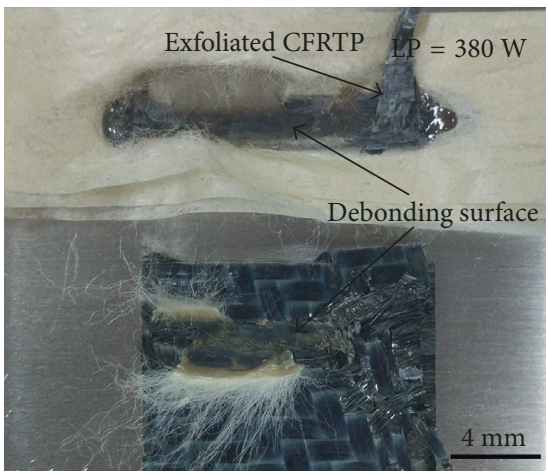

(d)

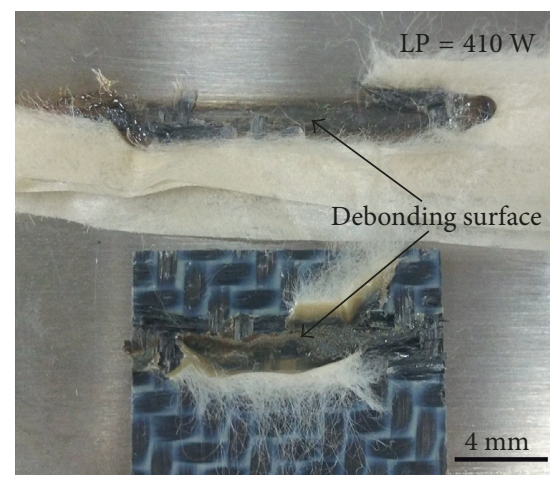

(e)

Figure 7: The morphology of debonding surface of the stainless steel/CFRTP joints with different laser power after tensile: (a) $290 \mathrm{~W}$; (b) $320 \mathrm{~W}$; (c) $350 \mathrm{~W}$; (d) $380 \mathrm{~W}$; (e) $410 \mathrm{~W}$.

joint with a laser power of $290 \mathrm{~W}$ has no PPS additive left on the CFRTP, which indicates the bonding force between CFRTP and PPS additive is lower than that between PPS additive and stainless steel. When the laser power increases, the amount of PPS additive remained on the CFRTP increases, and the air hole is observed on the stainless steel/CFRTP joints with a laser power of $350 \mathrm{~W}$ and $400 \mathrm{~W}$. This means that the decomposition of PPS additive occurs during the laser joining, which indicates the PPS additive is overheated. The redundant energy would lead the molten PPS to flow out of the gap of stainless steel and CFRTP, which decreases the shear strength. Moreover, the formation of the air hole along the interface is also detrimental to the bonding of the joint. As mentioned above, it could be concluded that the increasing laser power involves beneficial effects such as better squeezing of the PPS through the carbon fibers and higher removal of epoxy from the adhesion region. However, it also leads to larger bubbles and higher damage of the inner layers that tends to reduce the joints strength.

The statistical analysis of the surface of stainless steel/CFRTP joints with different power shows that the fusion width of the stainless steel increases with the laser power increasing and they almost have the linear relationship, as shown in Figure 8(a). Moreover, the fusion width of the PPS additive also increases with the laser power increase, but they do not have the linear relationship, as shown in Figure 8(b). Based on the observation of debonding surfaces, the PPS additive decomposes at the laser power above $350 \mathrm{~W}$, which would consume some energy and 


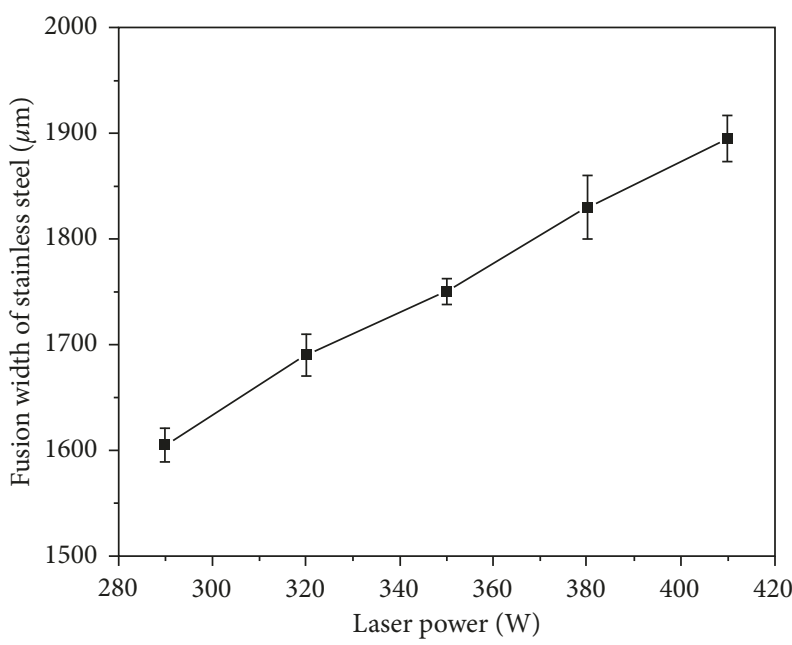

(a)

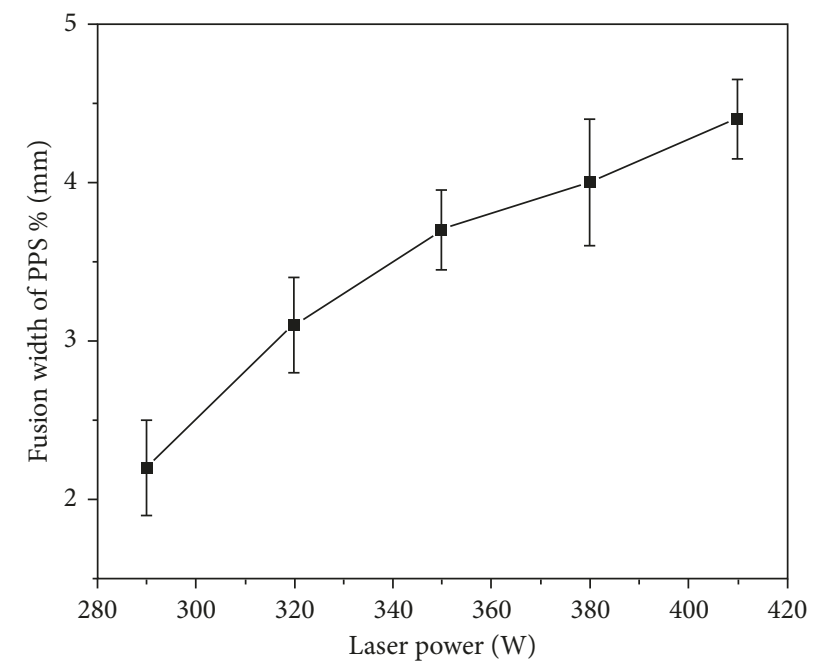

(b)

FIGURE 8: The fusion width of stainless steel (a) and the PPS additive (b) in the stainless steel/CFRTP joint with different laser power.

influence the width of the melted PPS additive [30]. In addition, the analysis of the surface of CFRTP of the $410 \mathrm{~W}$ specimen reveals that there are some $\mathrm{Cr}$ elements, which suggested that the diffusion between the stainless steel and CFRTP has taken place. Due to the mechanical bonding between PPS additive and stainless steel, the element diffusion suggests the high temperature of the melted PPS. Combining with the observation of debonding surface, it can be concluded that the excessive laser power could overheat the PPS additive, which results in its spreading and overflowing but decrease the bonding force with the stainless steel.

To explore the influence of laser scanning speed on the bonding force of stainless steel/CFRTP joint, the laser scanning speed is changed from $3 \mathrm{~mm} / \mathrm{s}$ to $7 \mathrm{~mm} / \mathrm{s}$. During the changing of laser scanning speed, the laser power, clamping pressure, and thickness of PPS were set as $320 \mathrm{~W}$, $0.5 \mathrm{MPa}$, and $300 \mu \mathrm{m}$, respectively. The shear strength of the stainless steel/CFRTP joints with different laser scanning speed is shown in Figure 9. It can be clearly seen that the shear strength of the stainless steel/CFRTP joint increases from $7 \mathrm{MPa}$ to $16 \mathrm{MPa}$ when the laser scanning speed increases from $3 \mathrm{~mm} / \mathrm{s}$ to $4 \mathrm{~mm} / \mathrm{s}$. At the laser scanning speed of $5 \mathrm{~mm} / \mathrm{s}$, the shear strength of the stainless steel/CFRTP joint just increases little. That indicates that the stainless steel/CFRTP joint could obtain the optimum value if the scanning speed is chosen between $4 \mathrm{~mm} / \mathrm{s}$ and $5 \mathrm{~mm} / \mathrm{s}$. When the laser scanning speed exceeds $5 \mathrm{~mm} / \mathrm{s}$, the shear strength of the stainless steel/CFRTP joint decreases sharply. The laser joined specimen with $7 \mathrm{~mm} / \mathrm{s}$ almost has no shear strength.

The observations of the debonding surfaces of the stainless steel/CFRTP joints with different laser scanning speed are given in Figure 10. It can be seen that morphology of the debonding surface changes with the laser scanning speed greatly. At the laser scanning speed of $3 \mathrm{~mm} / \mathrm{s}$, the surfaces of stainless steel and CFRTP both have the residual

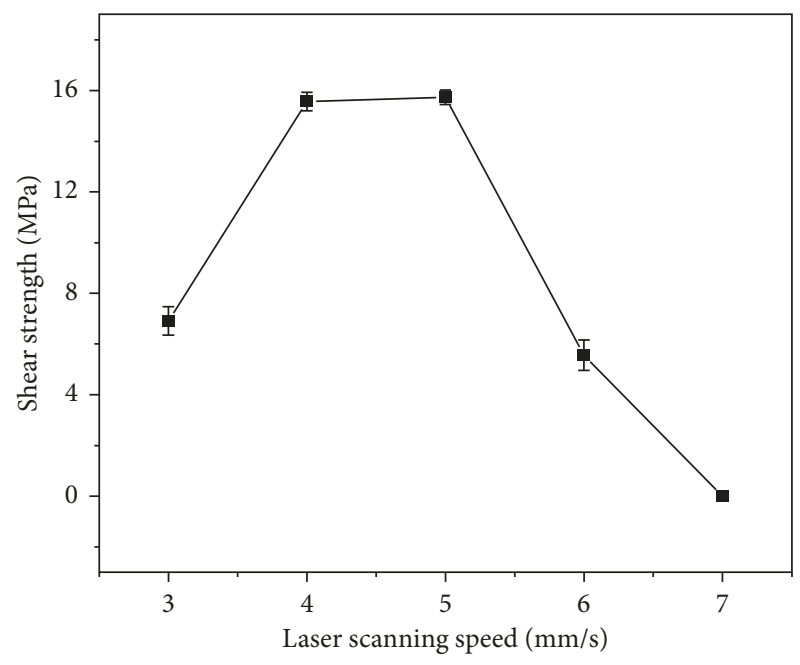

FIGURE 9: The shear strength of the stainless steel/CFRTP joints with different laser scanning speed.

melted PPS. But the surface of CFRTP exhibits the overheating feature, which is detrimental to the bonding effect. When the laser scanning speed increases to $4 \mathrm{~mm} / \mathrm{s}$ and $5 \mathrm{~mm} / \mathrm{s}$, there is obvious PPS residual on the surface of stainless steel and CFRTP, which indicates the bonding force of PPS additive with CFRTP and stainless steel is really good. Therefore, it could be understood that the stainless steel/CFRTP joints at the scanning speed below $5 \mathrm{~mm} / \mathrm{s}$ all have relative good shear strength. However, when the laser scanning speed is $6 \mathrm{~mm} / \mathrm{s}$ and $7 \mathrm{~mm} / \mathrm{s}$, there are few PPS additive adhered on the surface of stainless steel or CFRTP. Moreover, the laser joined specimen with laser scanning speed of $7 \mathrm{~mm} / \mathrm{s}$ has not melted the PPS thoroughly and coalesced with the CFRTP, which means that the heat released from the stainless steel is not high enough.

The statistical analysis of the debonding surfaces of the stainless steel/CFRTP joints with different laser scanning 


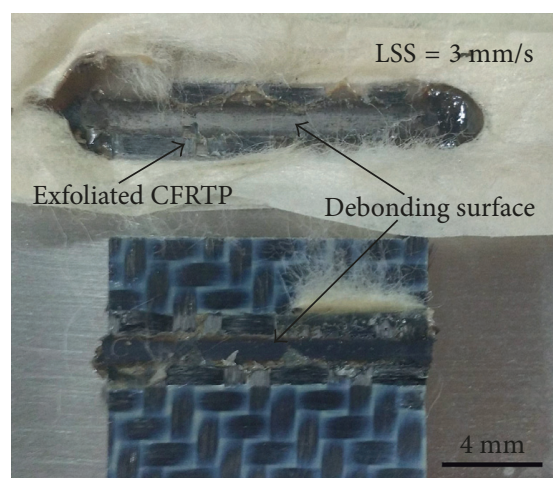

(a)

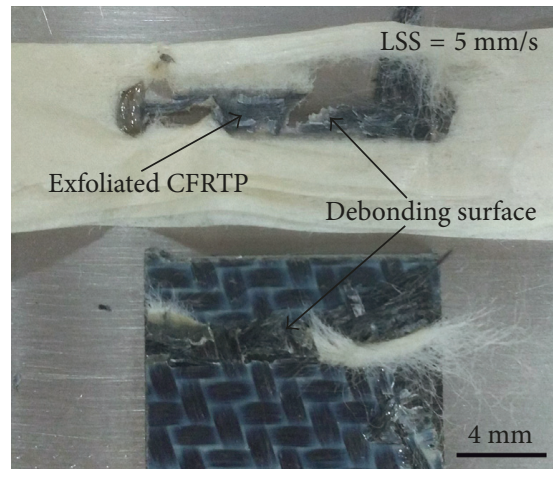

(c)

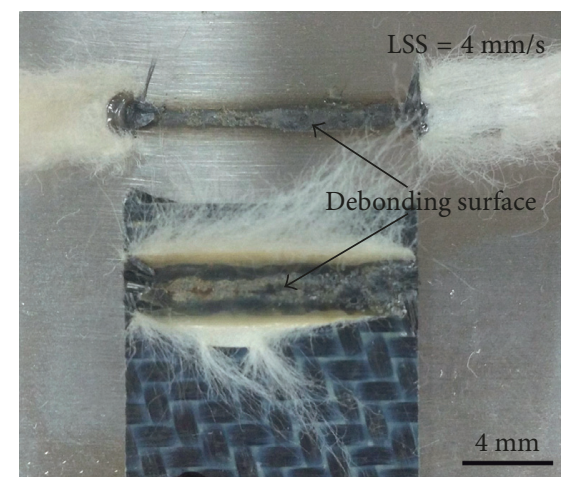

(b)

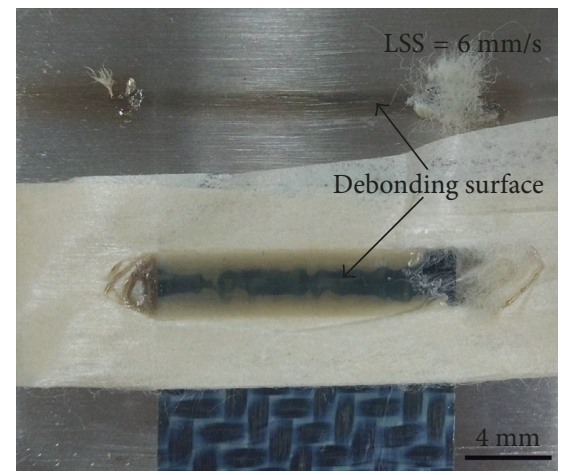

(d)

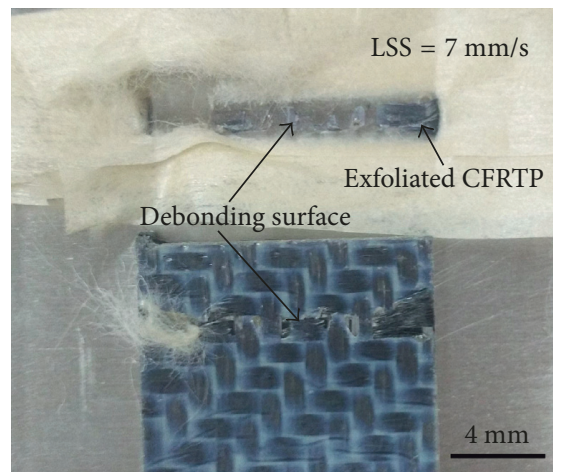

(e)

FIgURE 10: The morphology of debonding surface of the stainless steel/CFRTP joint with different laser scanning speed after tensile: (a) $3 \mathrm{~mm} / \mathrm{s}$, (b) $4 \mathrm{~mm} / \mathrm{s}$, (c) $5 \mathrm{~mm} / \mathrm{s}$, (d) $6 \mathrm{~mm} / \mathrm{s}$, and (e) $7 \mathrm{~mm} / \mathrm{s}$.

speed demonstrates that the fusion width of stainless steel decreases obviously with the laser scanning speed increase, as shown in Figure 11. Moreover, the fusion width of stainless steel almost has the linear relationship with the laser scanning speed. In combination with the observation on debonding surface, it can be concluded that the fast laser scanning speed cannot provide enough energy to the stainless steel. As a result, the heat transferred to the surface of CFRTP is limited which cannot melt the PPS additive. Based on the former researches [35], the bonding effect between the CFRTP and stainless steel is mainly influenced by the bonding interface. Due to the great difference between the stainless steel and CFRTP, there would be no atom or molecular binding. The melted PPS could be mechanical bonding with the stainless steel and molecular bonding with the CFRTP, so the energy from the laser is very important, which determines the state of the PPS additive.

3.3. Effect of Clamping Pressure and Thickness of PPS on the Laser Joining Stainless Steel and CFRTP. During the laser joining, the external factors of clamping pressure and thickness of PPS both have some impacts on the bonding force of the laser-processed stainless steel/CFRTP joint. To investigate their effects, the clamping pressure and thickness of PPS were changed gradually and the shear strength of the laser joining specimen was tested to evaluate the bonding force. During the investigation of the effect of clamping pressure, the laser power, laser scanning speed, and thickness of PPS were set as $320 \mathrm{~W}, 5 \mathrm{~mm} / \mathrm{s}$, and $300 \mu \mathrm{m}$, respectively. 


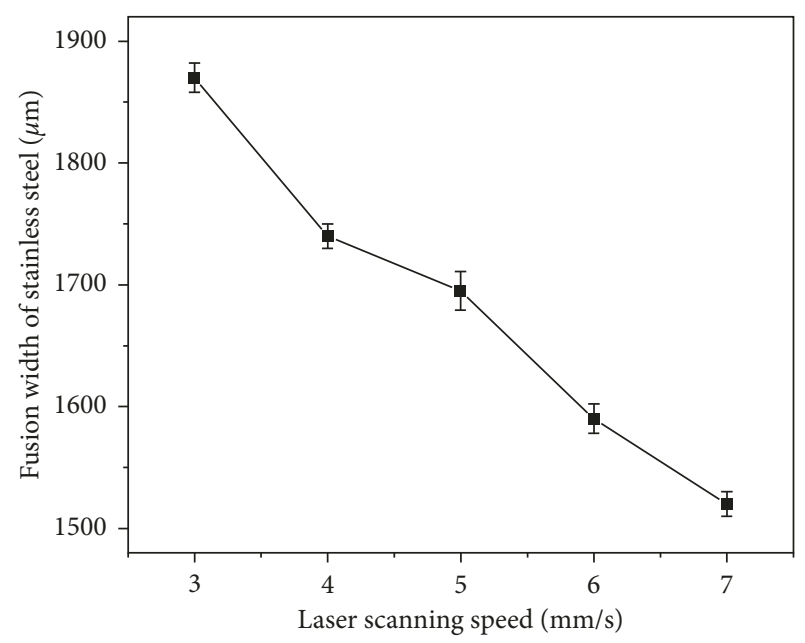

Figure 11: The fusion width of the stainless steel in the stainless steel/CFRTP joints with different laser scanning speed.

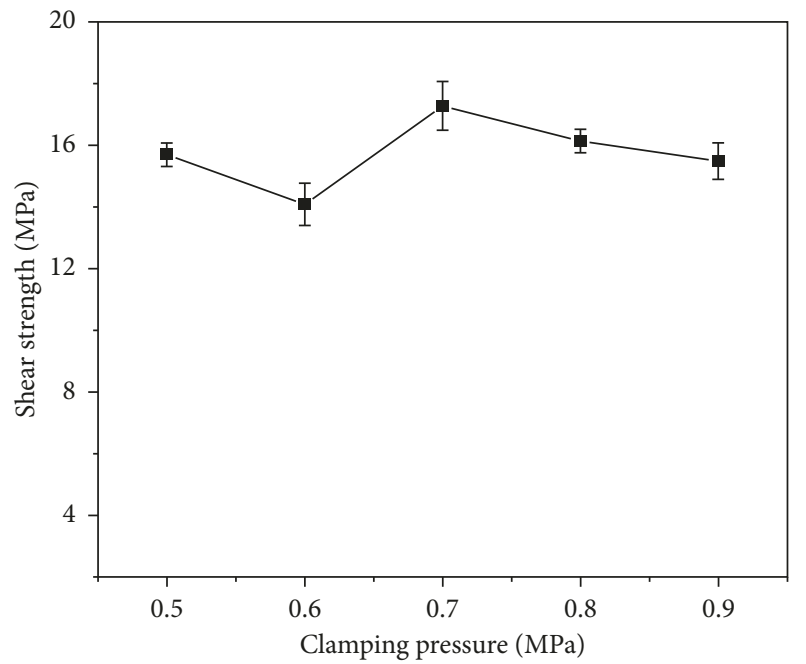

FIGURE 12: The shear strength of the stainless steel/CFRTP joint with different clamping pressure.

The variation of shear strength of the stainless steel/CFRTP joints with different clamping pressure is shown in Figure 12. The shear strength of the stainless steel/CFRTP joint decreases firstly and obtains the minimum value of $14 \mathrm{MPa}$ at clamping pressure $0.6 \mathrm{MPa}$; then, the shear strength increases to the maximum value of $17 \mathrm{MPa}$ at clamping pressure $0.7 \mathrm{MPa}$. After that, the shear strength decreases gradually with the increase of the clamping pressure. In general, the fluctuation of shear strength of the stainless steel/CFRTP joint is limited with the clamping pressure variation from $0.5 \mathrm{MPa}$ to $0.9 \mathrm{MPa}$.

The observations on debonding surfaces of the stainless steel/CFRTP joints with different clamping pressure are shown in Figure 13. It can be seen that the debonding surface is relatively clean without violent torn PPS on both surfaces. When the clamping pressure is lower than $0.7 \mathrm{MPa}$, the PPS additive mainly remains on the stainless steel, and the debonded surface contains the exfoliated CFRTP. And moreover, the stainless steel/CFRTP joints with $0.5 \mathrm{MPa}$ and 0.6 MPa have more exfoliated PPS on CFRTP. With the clamping pressure exceeding $0.7 \mathrm{MPa}$, the PPS almost totally remains on the CFRTP, and the fusion width of the PPS additive increases, compared with the joint with low clamping pressure.

The statistical analysis of the debonding surface reveals that the fusion width of the PPS additive increases greatly with the increase of clamping pressure when the clamping pressure is below 0.6 MPa, as shown in Figure 14. When the clamping pressure increases further, the fusion width of the PPS additive just increases a little before the clamping pressure reaches $0.8 \mathrm{MPa}$. The fusion width of the PPS additive even decreases, when the clamping pressure is $0.9 \mathrm{MPa}$. As shown in the observation above, the CFRTP is weaved from the carbon fibers and PPS, which makes the surface of CFRTP rough. During the laser joining, the gap between the stainless steel, PPS additive, and CFRTP would decrease the heat transfer efficiency. The increased clamping pressure could increase the contacting area between the CFRTP and the PPS, which is beneficial to the melting of PPS additive and the PPS in CFRTP. Therefore, it is easy to understand the increasing of fusion width of PPS with increased clamping pressure.

During the investigation of the effect of PPS additive thickness, the laser power, laser scanning speed, and clamping pressure are set as $320 \mathrm{~W}, 5 \mathrm{~mm} / \mathrm{s}$, and $0.5 \mathrm{MPa}$, respectively. The thickness of the PPS additive changed from 0 to $450 \mu \mathrm{m}$. The shear strength of the stainless steel/CFRTP joint with different PPS additive thickness is shown in Figure 15. It can be seen that the shear strength of the stainless steel/CFRTP joint increases with the thickness of PPS additive and obtains the maximum value of $15 \mathrm{MPa}$ at $300 \mu \mathrm{m}$. When the thickness of PPS additive increases to $450 \mu \mathrm{m}$, the shear strength of the laser joined specimen drops significantly and is lower than that without PPS additive.

The observations of the debonding surfaces of the stainless steel/CFRTP joints with different thickness of PPS additive are shown in Figure 15. It can be found that the CFRTP still can be joined on the stainless steel without PPS additive, as shown in Figure 16(a). Due to the weave structure of the CFRTP, the distribution of melted PPS on the surface of stainless steel is not homogeneous. Moreover, the decomposition of PPS in CFRTP can be observed on the debonding surface of CFRTP, which would lead to the formation of air bubbles and be detrimental to the bonding force. When the thickness of PPS additive increases to $150 \mu \mathrm{m}$, the melted PPS additive attached on the surface of stainless steel is thin and relatively homogeneous, as shown in Figure 16(b). Furthermore, the melted PPS additive fills in the vacancy of the CFRTP surface, and some carbon fibers are exfoliated from the CFRTP. On the debonding surface of the stainless steel/CFRTP joint with $300 \mu \mathrm{m}$ PPS additive, one can observe the PPS additive is melted and adhered on the stainless steel surface perfectly, as shown in Figure 16(c). A layer of carbon fiber is exfoliated from the CFRTP and adhered on the CFRTP uniformly, which suggests that the PPS additive has good bonding with the stainless steel. When the thickness of PPS additive increases to $450 \mu \mathrm{m}$, the PPS additive is adhered on the stainless steel but the CFRTP surface almost has no melting feature, as shown in Figure 16(d). The further observation finds there is some small 


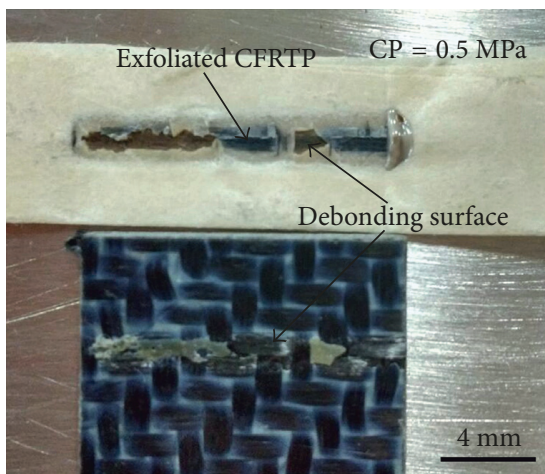

(a)

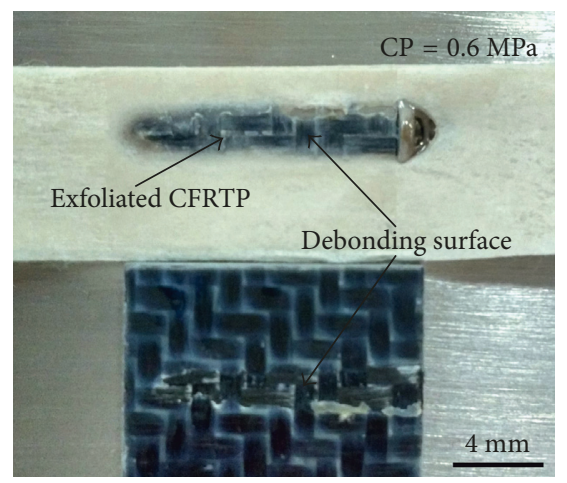

(b)

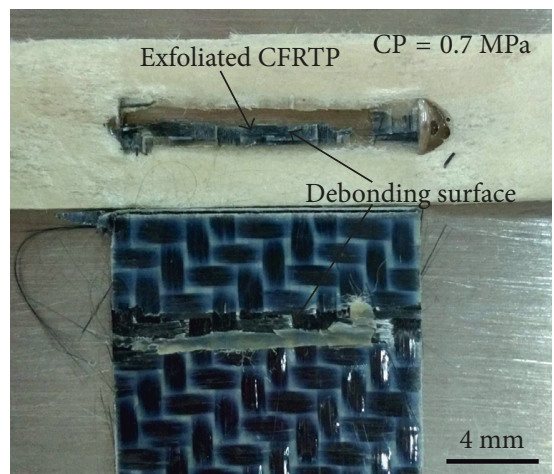

(c)

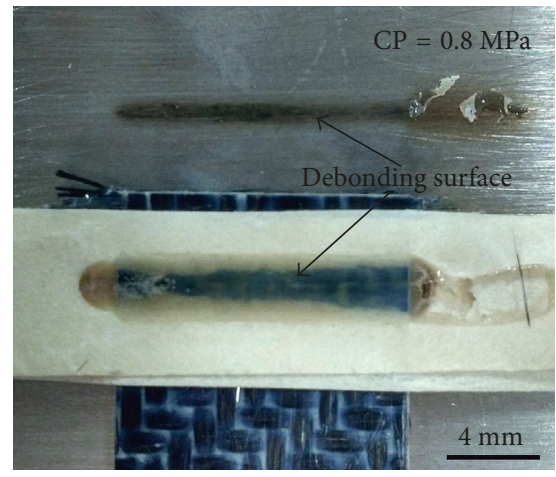

(d)

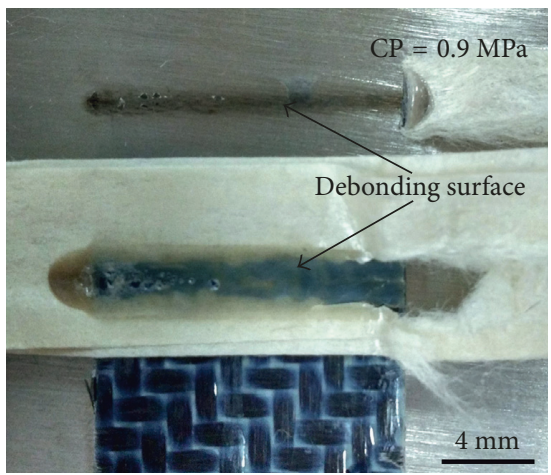

(e)

FIGURE 13: The morphology of debonding surface of the stainless steel/CFRTP joints with different clamping pressure after tensile: (a) $0.5 \mathrm{MPa}$, (b) $0.6 \mathrm{MPa}$, (c) $0.7 \mathrm{MPa}$, (d) $0.8 \mathrm{MPa}$, and (e) $0.9 \mathrm{MPa}$.

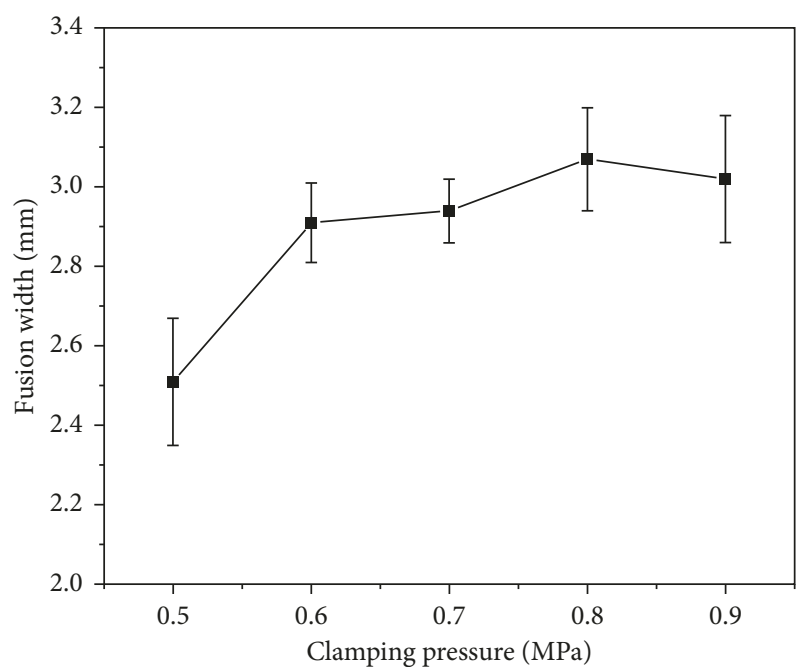

FIGURE 14: The fusion width of the PPS additive in the stainless steel/CFRTP joints with different clamping pressure.

delaminated PPS additive which adhered on the corresponding region of the CFRTP surface.

The observation of the cross section of the stainless steel/CFRTP joints with different thickness of PPS additive exhibits that more or less the addition of PPS additive would result in the formation of air bubbles, as shown in Figure 16. When the thickness of PPS additive is $150 \mu \mathrm{m}$, the decomposed PPS can be found along the interface of CFRTP and stainless

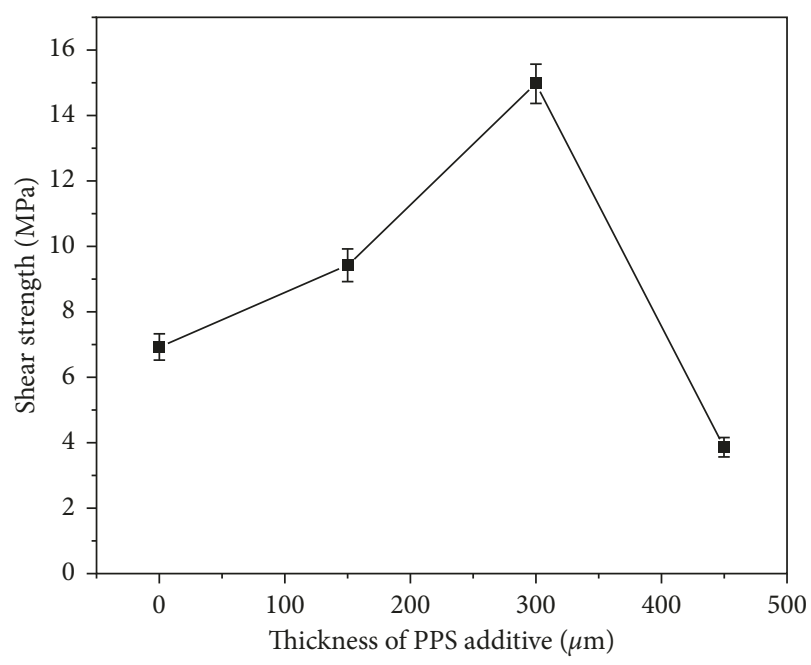

FIGURE 15: The shear strength of the stainless steel/CFRTP joints with different thickness of PPS additive.

steel, as shown in Figure 17(a). The decomposed regions have the sphere- or rod-like shape, which may be ascribed to the insufficient PPS additive and the morphology of CFRTP. According the recent researches $[26,36]$, the decomposition of PPS additive is detrimental to the interface adhesion. When the thickness of PPS additive increases to $300 \mu \mathrm{m}$, the stainless steel/CFRTP joint obtains clear and well-bonded interface, as shown in Figure 17(b). No decomposition and air bubble occur 


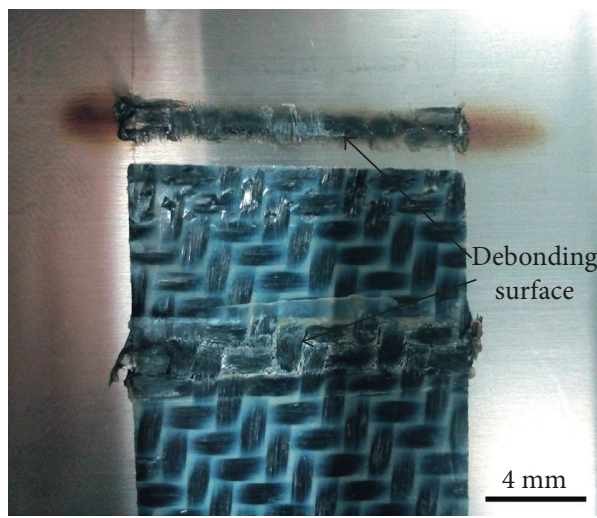

(a)

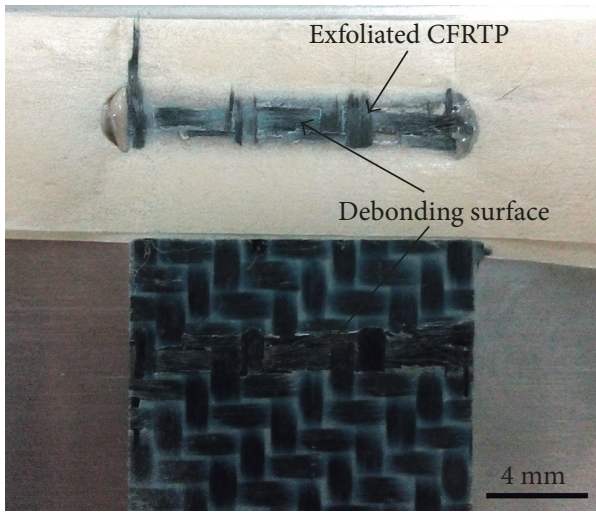

(c)

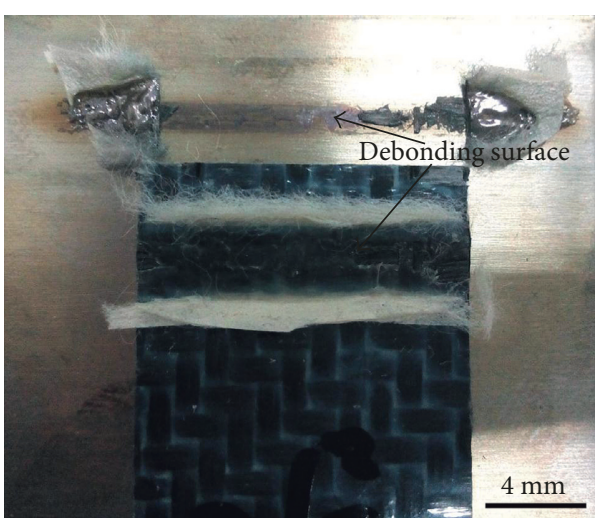

(b)

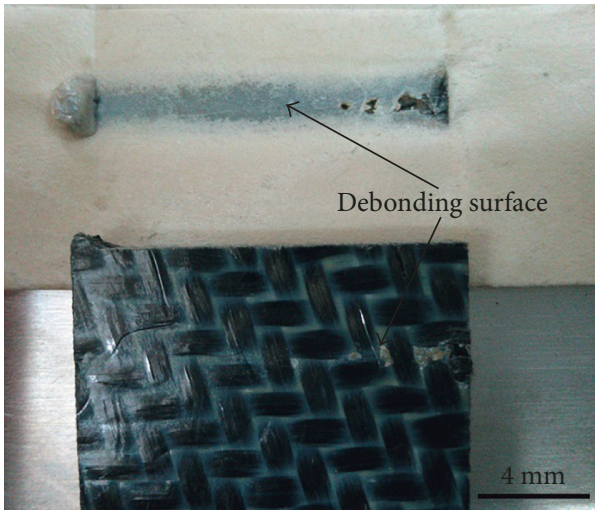

(d)

FIGURE 16: The morphology of debonding surface of the stainless steel/CFRTP joints with different PPS addition thickness after tensile: (a) 0 , (b) $150 \mu \mathrm{m}$, (c) $300 \mu \mathrm{m}$, and (d) $450 \mu \mathrm{m}$.

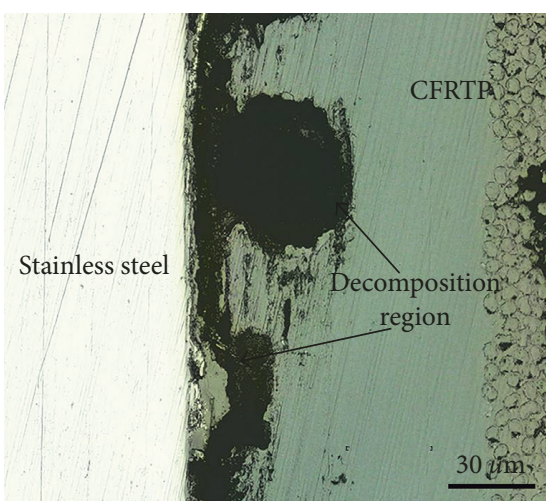

(a)

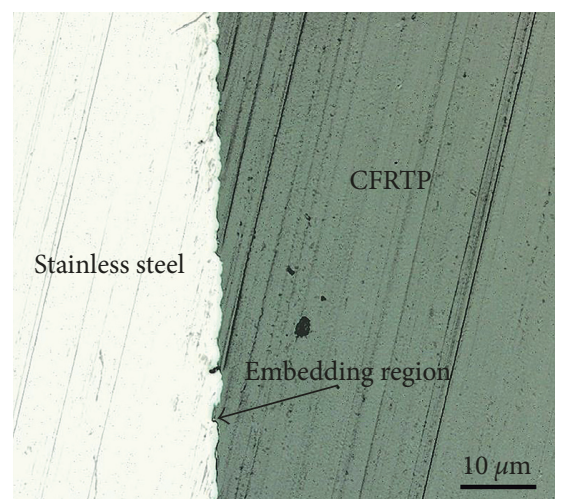

(b)

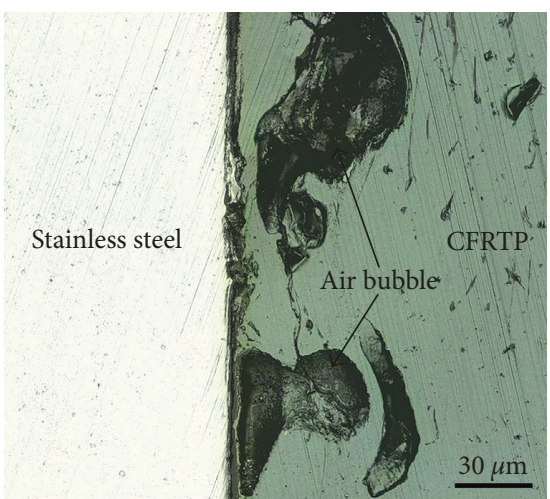

(c)

FIGURE 17: The interface morphology of the stainless steel/CFRTP joints with different PPS addition thickness: (a) $150 \mu \mathrm{m}$, (b) $300 \mu \mathrm{m}$, and (c) $450 \mu \mathrm{m}$.

in the PPS, which indicates that the sufficient PPS additive could benefit the joining of stainless steel and CFRTP. However, on the cross section of the laser joined specimen with $450 \mu \mathrm{m}$ PPS additive, the air bubbles with big size form in the melted PPS and mostly distribute in the PPS adjacent to the interface, as shown in Figure 17(c). In addition, the crack connecting the air bubbles is observed. Combining with the observation on debonding surface, the PPS additive is adhered on the stainless steel without decomposition, so the formation of air bubbles should be ascribed to the increased PPS, which could decrease the heat concentration and the fluidity of the molten PPS. Then, the clamping pressure could not compel the residual or generated air out of the melted PPS additive during the laser joining and result in the formation of air bubble.

Based on the previous researches [25, 27], the bonding force of the laser joined CFRTP and metal is mainly 


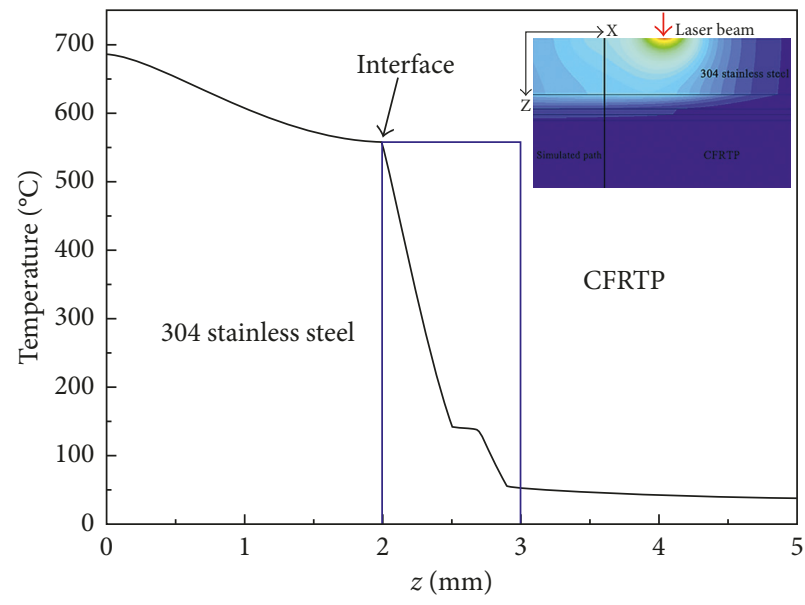

(a)

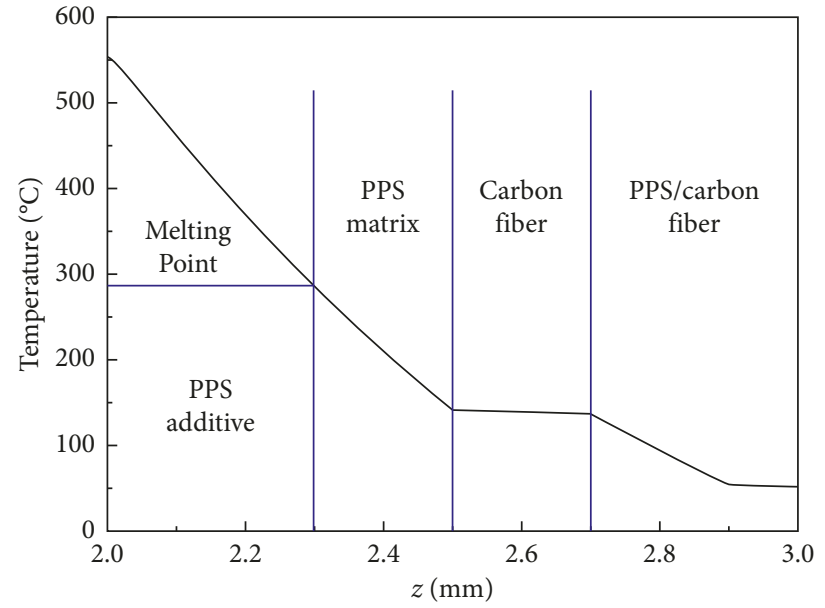

(b)

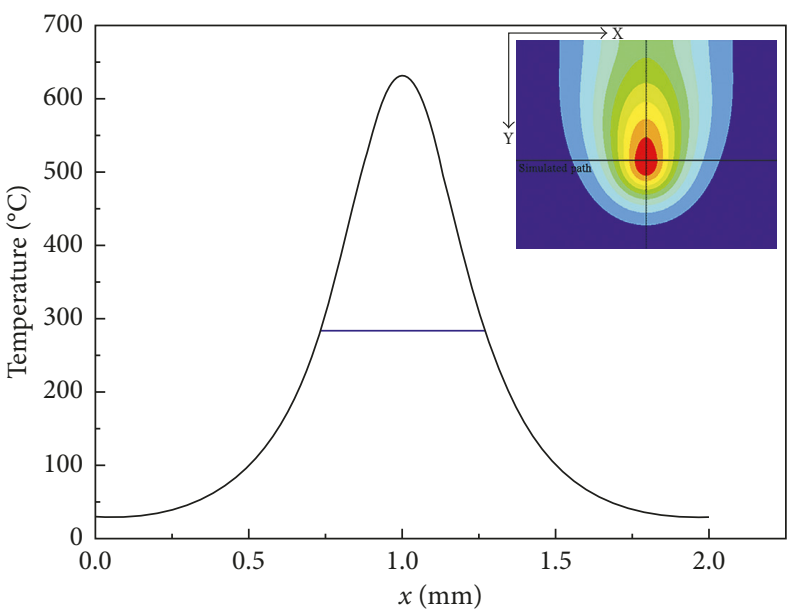

(c)

FIgURE 18: (a) The temperature distribution of the stainless steel/CFRTP joint along the cross section; (b) the amplified curve in the blue rectangle in (a) showing temperature distribution along the depth of the PPS additive and CFRTP; (c) the temperature distribution on the surface of PPS additive.

determined by the external energy which remelts the PPS additive and PPS matrix of the CFRTP. Therefore, it can be understood that the bonding force of the stainless steel/CFRTP joint exhibits parabolic tendency with the variation of laser power and scanning speed. Because the high laser power and low scanning speed would result in excessive energy, that promotes the decomposition of PPS and the overflow of melted PPS. The decomposition of PPS would release gas and form the air bubble, which weakens the bonding between the stainless steel and CFRTP. Moreover, the overflow of PPS also decreases the bonding transition region between the stainless steel and CFRTP, which is detrimental to the bonding force. However, if the laser power is low and the laser scanning speed is high, the absorbed heat of the PPS would be insufficient, especially the PPS in CFRTP. As a result, the PPS adjacent to the CFRTP and PPS on the surface of CFRTP could not be melted thoroughly. Then, the merging between the PPS additive and CFRTP would be influenced. The simulation analysis on the temperature distribution of the stainless steel/CFRTP joint fabricated with laser power $320 \mathrm{~W}$, scanning speed $5 \mathrm{~mm} / \mathrm{s}$, and laser beam radius $0.25 \mathrm{~mm}$ is shown in Figure 18. It can be found that the laser processing generates great energy concentration on the surface of stainless steel. Due to the heat transfer, the maximum temperature adjacent to the interface of stainless steel/PPS additive is a little late, compared with the stainless steel surface. However, the temperature drops greatly when the position goes far away from the interface. At the interface of stainless steel and PPS additive, the temperature reaches $560^{\circ} \mathrm{C}$ which is much higher than the melting point of the PPS. Therefore, the heat from the laser scanned stainless steel would melt the PPS between the stainless steel and CFRTP. However, there are obvious stages between the stainless steel and CFRTP. The temperature drops sharply in the PPS additive and almost reaches the melting point on the PPS matrix surface if the PPS additive is $300 \mu \mathrm{m}$. This indicates that the heat would be sufficient enough to melt the PPS matrix and merge it with the PPS additive. With the position going into the CFRTP, the temperature decreases below the melting point. Moreover, the rapid temperature decreasing also 
suggests that the energy from laser should be increased if the PPS additive and PPS in the CFRTP surface needs to be melted and merged absolutely. The simulated result on the PPS additive also exhibits a fusion region with a width of $0.5 \mathrm{~mm}$ has the temperature above the melting point, which indicates the PPS additive in such a region would be melted. Such simulated results confirm the experimental observation above. The bonding effect of the stainless steel/CFRTP is mainly affected by the laser power and laser scanning speed which determines the absorbed energy.

Except the external energy, the clamping pressure and PPS additive also play an important role in affecting the bonding force of the laser joined stainless steel/CFRTP joint. According to the recent studies $[26,36]$, the thermal joining between the stainless steel and CFRTP is mainly by mechanical bonding. However, [6] also reveals that the thermal joining would promote the metal element diffusion from the stainless steel to melted PPS, which forms the new ion bond with the molecular bond of PPS and improves the bonding strength between the stainless steel and CFRTP. To achieve such an objective, the melted PPS should be attached to the stainless steel closely and cooperated with some additive. Therefore, the appropriate clamping pressure should be exerted on the stainless steel and CFRTP. The excessive clamping pressure would result in the overflow of melted PPS, which decreases the transition layer between the stainless steel and CFRTP. Furthermore, the overflow of melted PPS could destroy the formed bonds between the ion and molecule, which is detrimental to the bonding strength. Therefore, to achieve optimum bonding strength, the clamping pressure and PPS additive thickness should be appropriate and they should cooperate with each other.

\section{Conclusions}

(1) The CFRTP can be joined with the 304 stainless steel by the fiber laser, but the laser scanning on the stainless steel results in the formation of the fusion zone and heat-affected zone. In the heat-affected zone, the lathy ferrite precipitates along the boundary, which refines the austenite, while in the fusion zone, the ferrite forms the skeletal structure and separates the austenite into small cellular structure. Compared with the original microstructure of stainless steel, the laser joining refines the microstructure in the fusion and heat-affected zones.

(2) With the increase of laser power and scanning speed, the shear strength of the laser joined stainless steel/CFRTP joint increases firstly and then decreases. The high laser power or low laser scanning speed would overheat the PPS and lead to the decomposition. However, the low laser power or high laser scanning speed would reduce the transferred heat and lead to the insufficiently melting of PPS. The stainless steel/CFRTP joint obtains the maximum value at the laser power of $320-350 \mathrm{~W}$ and laser scanning speed of $4-5 \mathrm{~mm} / \mathrm{s}$.
(3) The variation of clamping pressure exerts small impact on the shear strength of the stainless steel/CFRTP joint which fluctuates from $14 \mathrm{MPa}$ to $17 \mathrm{MPa}$. The increase of clamping pressure may promote the flow of molten PPS and the appropriate clamping pressure could be $0.7 \mathrm{MPa}$.

(4) Without the PPS additive, the laser joining could connect the CFRTP and stainless steel but overheat the PPS in the CFRTP and cause its decomposition. The increased thickness of PPS additive improves the shear strength, and the optimal PPS additive thickness is $300 \mu \mathrm{m}$. More or less PPS additive would result in obvious decomposition or air bubbles.

\section{Data Availability}

The data used to support the findings of this study are available from the corresponding author upon request.

\section{Conflicts of Interest}

The authors declare that they have no conflicts of interest.

\section{Acknowledgments}

The authors are grateful to the Shenzhen Basic Research Project (JCYJ20150529162228734, JCYJ20150625155931806, JCYJ20160427100211076, and JCYJ20160427170611414) and the Shenzhen Technology Innovation Plan (CXZZ20140731091722497 and CXZZ20140419114548507).

\section{References}

[1] X. L. Zhao and L. Zhang, "State-of-the-art review on FRP strengthened steel structures," Engineering Structures, vol. 29, no. 8, pp. 1808-1823, 2007.

[2] F. Lambiase, S. Genna, C. Leone, and A. Paoletti, "Laserassisted direct-joining of carbon fibre reinforced plastic with thermosetting matrix to polycarbonate sheets," Optics and Laser Technology, vol. 94, pp. 45-58, 2017.

[3] G. Williams, R. Trask, and I. Bond, "A self-healing carbon fiber reinforced polymer for aerospace applications," Composites Part A: Applied Science and Manufacturing, vol. 38, no. 6, pp. 1525-1532, 2007.

[4] A. Mayyas, A. Qattawi, M. Omar, and D. Shan, "Design for sustainability in automotive industry: a comprehensive review," Renewable and Sustainable Energy Reviews, vol. 16, no. 4, pp. 1845-1862, 2012.

[5] K. W. Neale, "FRPs for structural rehabilitation: a survey of recent progress," Progress in Structural Engineering and Materials, vol. 2, no. 2, pp. 133-138, 2000.

[6] Z. Zhang, J. Shan, X. Tan, and J. Zhang, "Improvement of the laser joining of CFRP and aluminum via laser pre-treatment," International Journal of Advanced Manufacturing Technology, vol. 90, no. 9-12, pp. 3465-3472, 2017.

[7] L. Y. Sheng, B. N. Du, C. Lai, J. T. Guo, and T. F. Xi, "Influence of tantalum addition on microstructure and mechanical properties of the NiAl-based eutectic alloy," Strength of Materials, vol. 49, no. 1, pp. 109-117, 2017.

[8] L. Sheng, F. Yang, J. Guo, and T. Xi, "Anomalous yield and intermediate temperature brittleness behaviors of directionally solidified nickel-based superalloy," Transactions of 
Nonferrous Metals Society of China, vol. 24, no. 3, pp. 673-681, 2014.

[9] G. Marannano and B. Zuccarello, "Numerical experimental analysis of hybrid double lap aluminum-CFRP Joints," Composites Part B: Engineering, vol. 71, pp. 28-39, 2015.

[10] J. Kweon, J. Jung, T. Kim, J. Choi, and D. Kim, "Failure of carbon composite-to-aluminum joints with combined mechanical fastening and adhesive bonding," Composite Structures, vol. 75, no. 1-4, pp. 192-198, 2006.

[11] P. P. Camanho, A. Fink, A. Obst, and S. Pimenta, "Hybrid titanium-CFRP laminates for high-performance bolted joints," Composites Part A: Applied Science and Manufacturing, vol. 40, no. 12, pp. 1826-1837, 2009.

[12] F. Lambiase and A. Paoletti, "Friction-assisted clinching of aluminum and CFRP sheets," Journal of Manufacturing Processes, vol. 31, pp. 812-822, 2018.

[13] F. Lambiase and D.-C. Ko, "Two-steps clinching of aluminum and carbon fiber reinforced polymer sheets," Composite Structures, vol. 164, pp. 180-188, 2017.

[14] F. Lambiase and D.-C. Ko, "Feasibility of mechanical clinching for joining aluminum AA6082-T6 and carbon fiber reinforced polymer sheets," Materials and Design, vol. 107, pp. 341-352, 2016.

[15] K. Ishii, M. Imanaka, H. Nakayama, and H. Kodama, "Fatigue failure criterion of adhesively bonded CFRP/metal joints under multiaxial stress conditions," Composites Part A: Applied Science and Manufacturing, vol. 29, no. 4, pp. 415-422, 1998.

[16] P. Molitor, V. Barron, and T. Young, "Surface treatment of titanium for adhesive bonding to polymer composites: a review," International Journal of Adhesion and Adhesives, vol. 21, no. 2, pp. 129-136, 2001.

[17] F. Lambiase and A. Paolettia, "Mechanical behavior of AA5053/polyetheretherketone (PEEK) made by friction assisted joining," Composite Structures, vol. 189, pp. 70-77, 2018.

[18] F. Lambiase, A. Paolettia, V. Grossix, and A. Di Ilio, "Friction assisted joining of aluminum and PVC sheets," Journal of Manufacturing Processes, vol. 29, pp. 221-222, 2017.

[19] F. Lambiase, A. Paolettia, V. Grossi, and S. Genn, "Improving energy efficiency in friction assisted joining of metals and polymers," Journal of Materials Processing Technology, vol. 250, pp. 379-389, 2017.

[20] F. Lambiase and S. Genna, "Laser-assisted direct joining of AISI304 stainless steel with polycarbonate sheets: thermal analysis, mechanical characterization, and bonds morphology," Optics and Laser Technology, vol. 88, pp. 205-214, 2017.

[21] F. Lambiase, S. Genna, and R. Kant, "A procedure for calibration and validation of FE modeling of laser-assisted metal to polymer direct joining," Optics and Laser Technology, vol. 98, pp. 363-372, 2018.

[22] S. Katayama and Y. Kawahito, "Laser direct joining of metal and plastic," Scripta Materialia, vol. 59, no. 12, pp. 1247-1250, 2008.

[23] X. Tan, J. Shan, and J. Ren, "Effects of Cr plating layer on shear strength and interface bonding characteristics of mild steel/ CFRP joint by laser heating," Acta Metallurgica Sinica, vol. 49, no. 6, pp. 751-756, 2013.

[24] A. Roesner, A. Olowinsky, and A. Gillner, "Long term stability of laser joined plastic metal parts," Physics Procedia, vol. 41, pp. 169-171, 2013.

[25] X. H. Tan, J. Zhang, J. G. Shan, S. L. Yang, and J. L. Ren, "Characteristics and formation mechanism of porosities in
CFRP during laser joining of CFRP and steel," Composites Part B: Engineering, vol. 70, pp. 35-43, 2015.

[26] K. Nagatsuka, S. Yoshida, A. Tsuchiy, and K. Nakata, "Direct joining of carbon-fiber-reinforced plastic to an aluminum alloy using friction lap joining," Composites Part B: Engineering, vol. 73, pp. 82-88, 2015.

[27] J. K. Jiao, Q. Wang, F. Y. Wang, S. P. Zan, and W. W. Zhang, "Numerical and experimental investigation on joining CFRTP and stainless steel using fiber lasers," Journal of Materials Processing Technology, vol. 240, pp. 362-369, 2017.

[28] J. K. Jiao, Z. F. Xu, Q. Wang, L. Y. Sheng, and W. W. Zhang, "CFRTP and stainless steel laser joining: thermal defects analysis and joining parameters optimization," Optics and Laser Technology, vol. 103, pp. 170-176, 2018.

[29] L. Y. Sheng, F. Yang, T. F. Xi, C. Lai, and H. Q. Ye, "Influence of heat treatment on interface of $\mathrm{Cu} / \mathrm{Al}$ bimetal composite fabricated by cold rolling," Composites Part B: Engineering, vol. 42, no. 6, pp. 1468-1473, 2011.

[30] K. W. Jung, Y. Kawahito, and S. Katayama, "Laser direct joining of carbon fibre reinforced plastic to stainless steel," Science and Technology of Welding and Joining, vol. 16, no. 8, pp. 676-680, 2011.

[31] M. Wahba, Y. Kawahito, and S. Katayama, "Laser direct joining of AZ91D thixomolded $\mathrm{Mg}$ alloy and amorphous polyethylene terephthalate," Journal of Materials Processing Technology, vol. 211, no. 6, pp. 1166-1174, 2011.

[32] J. C. Lippold and D. J. Kotecki, Welding Metallurgy and Weldability of Stainless Steels, John Wiley \& Sons Inc, Hoboken, NJ, USA, 2005.

[33] M. Alali, I. Todd, and B. P. Wynne, "Through-thickness microstructure and mechanical properties of electron beam welded $20 \mathrm{~mm}$ thick AISI 316L austenitic stainless steel," Materials and Design, vol. 130, pp. 488-500, 2017.

[34] L. Y. Sheng, F. Yang, T. F. Xi, Y. F. Zheng, and J. T. Guo, "Microstructure and room temperature mechanical properties of NiAl-Cr(Mo)-(Hf, Dy) hypoeutectic alloy prepared by injection casting," Transactions of Nonferrous Metals Society of China, vol. 23, no. 4, pp. 983-990, 2013.

[35] S. M. Goushegir, J. F. Santos, and S. T. Amancio-Filho, "Failure and fracture micro-mechanisms in metal-composite single lap joints produced by welding-based joining techniques," Composites Part A: Applied Science and Manufacturing, vol. 81, pp. 121-128, 2016.

[36] A. Pramanik, A. K. Basak, Y. Dong et al., "Joining of carbon fibre reinforced polymer (CFRP) composites and aluminium alloys-a review," Composites Part A: Applied Science and Manufacturing, vol. 101, pp. 1-29, 2017. 


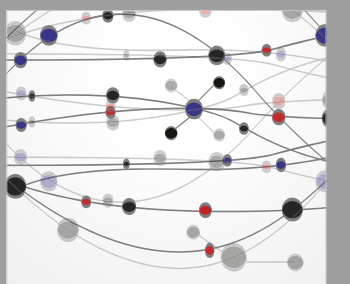

The Scientific World Journal
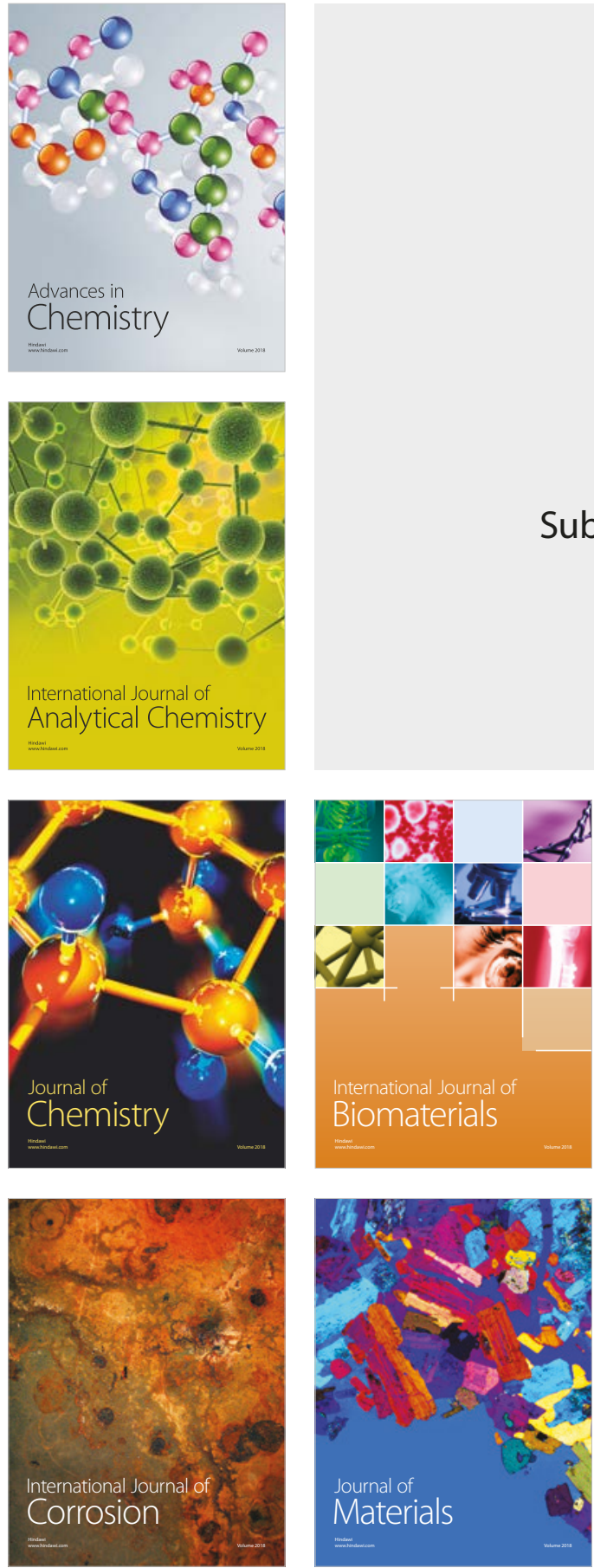

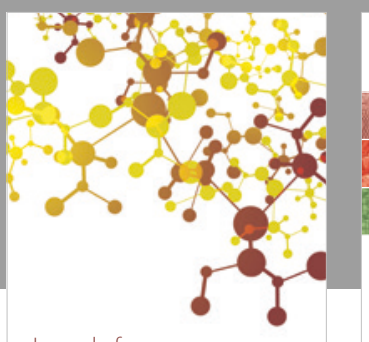

Journal of

Applied Chemistry
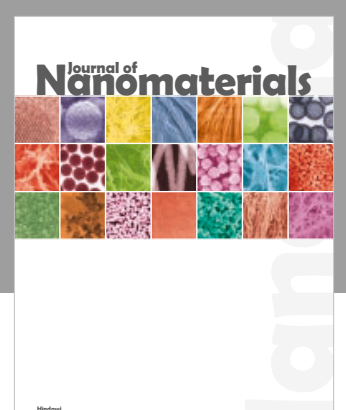

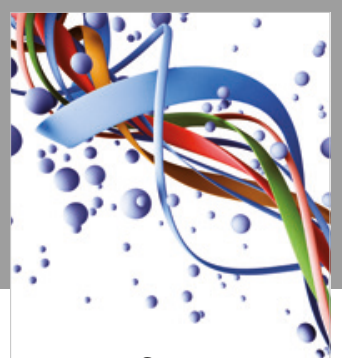

Scientifica

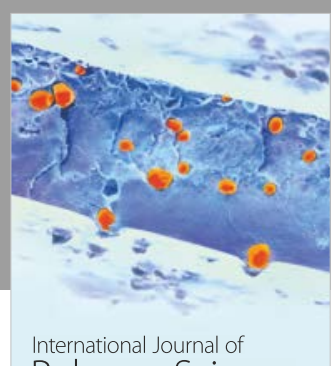

Polymer Science

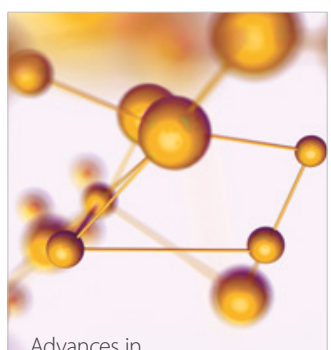

Physical Chemistry
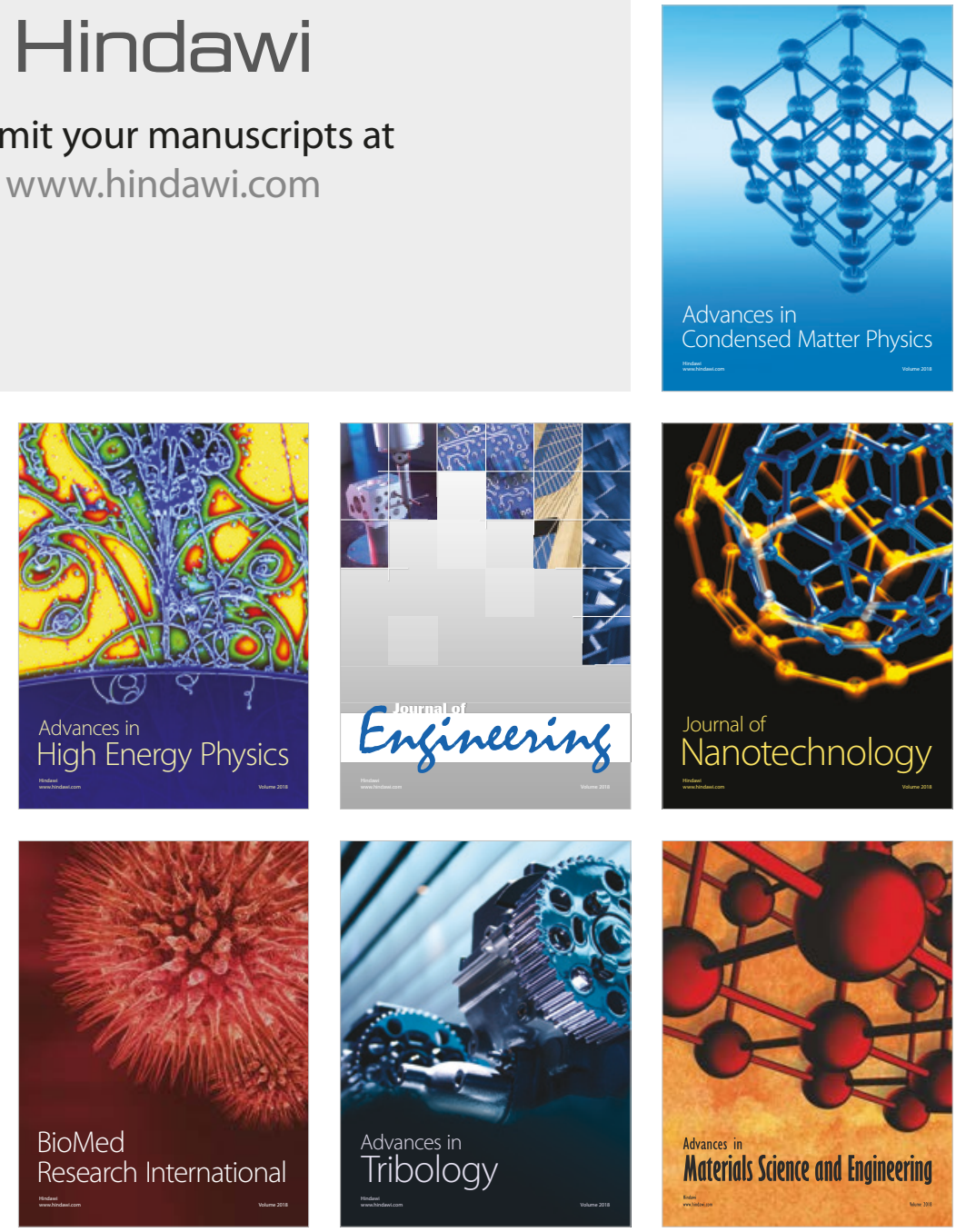